\title{
Mirabilis expansa Grown in Southern Illinois: Amino Acid Percentages Relative to Soil Amendments
}

\author{
Miriam Kritzer Van Zant ${ }^{*}$, William J. Banz², Gary Apgar², and David A. Lightfoot ${ }^{1}$ \\ ${ }^{1}$ Department of Plant, Soil and General Agriculture, Southern Illinois University, Carbondale, Carbondale, \\ IL 62901-4415, USA; ${ }^{2}$ Department of Animal Science, Food, and Nutrition, Southern Illinois University, \\ Carbondale, IL 62901-4317, USA
}

Received: January 16, 2019 / Accepted: October 5, 2019

\begin{abstract}
Effects of plant structure and soil amendments, on percentages of amino acids, were examined with three hypotheses for two crop varieties, of rare, ancient, drought resistant, indigenous, Andean, Mirabilis expansa (Ruiz and Pav.) Standl. (Nyctaginaceae), grown in southern Illinois. ANOVA and LS-Means analyses were run as pair-wise comparisons. Percentages of amino acids, crude protein, and total protein were dependent variables. Soil amendments, structure, and variety, were independent variables. Independent variable levels were percentages of soil amendments peat and steer manure, used to amend sand plots when constructed, growth above vs below ground, and each variety. Significance for $p$-values was at .05 or less. ANOVAs indicated several amino acids were present in significantly different amounts between roots and leafy parts of plants. There were statistically inconsistent effects from peat, and slight significance from steer manure. Exploratory analyses also indicated significantly different amounts of some amino acids between varieties, and for both above and below ground growth.
\end{abstract}

Keywords: Amino acid profiles; Mirabilis expansa; soil amendments; variety; structure; Nyctaginaceae.

Abbreviations: Indispensable amino acids: ARG, arginine; HIS, histidine; ISO, isoleucine; LEU, leucine; LYS, lysine; MET, methionine; PHE, phenylalanine; THR, threonine; TRY, tryptophan; VAL, valine. Dispensable amino acids: ALA, alanine; ASP, aspartic acid; CYS, cysteine; GLU, glutamic acid; GLY, glycine; HPR, hydroxyproline; HLY, hydroxylysine; LAN, lanthionine; ORN, ornithine; PRO, proline; SER, serine; TAU, taurine; TYR, tyrosine. Total amino acids: CRDP, crude protein; TOTP, total protein. EXT, Extended, applies to tables in Appendix C-7 of Kritzer Van Zant's dissertation (2016a); SI, Supporting Information. Table abbreviations are given in the notes for each table.

\section{Introduction}

Changing growth conditions have been shown to affect percentages of amino acids in plants (Thanapornpoonpong et al., 2008; Li et al., 2013). Two Mirabilis expansa (Ruiz and Pav.) Standl. (Nyctaginaceae) crop varieties have been shown to be protein machines, that need little water or fertilizer to produce large amounts of high quality, complete protein (Kritzer Van Zant 2016a, 2016b, 2017; Kritzer Van Zant et al. 2018, 2019). There is a need for modern processing methods for $M$. expansa to become more important to modern agriculture (Kritzer Van Zant 2016a, 2016b; Kritzer Van Zant et al. 2019). Percentages of indispensable amino acids produced in two crop varieties of $M$. expansa during a growth study in southern Illinois (Kritzer Van Zant, 2016a; Kritzer Van Zant et al., 2018, 2019), were examined for effects of independent variables in three hypotheses. Independent variables were soil amendments peat and steer manure, added to sand plots used to grow the $M$. expansa material at the time of construction, as well as plant structures including herbage and roots, and the two varieties.

Results are reported from ANOVAs and Tukey-adjusted LSMeans analyses. Tukey-adjusted LS-Means results showed which variable level combinations supported significance for each pair of independent variables. Two additional independent

\footnotetext{
"Corresponding author: mkvzant@gmail.com
}

This is an Open Access article distributed under the terms of the Creative Commons Attribution License (http://creativecommons.org/licenses/by/3.0/), which permits unrestricted use, distribution, and reproduction in any medium, provided the original work is properly cited. 
variables, variety, for which both varieties were submitted to statistical analyses simultaneously, and COA (combined organic amendments), which incorporated all of the plots containing peat, steer manure, or both, simultaneously, were also analyzed in ANOVAs and Tukey-adjusted LS-Means. Dependent variables were percentages of each amino acid tested, CRDP (crude protein) and TOTP (total protein). Significant $p$-values were less than or equal to 0.05 . Due to small sample sizes, differences in years of production between varieties, and variation in amounts of amendments in plots used for growing each variety, all analyses were run as pair-wise comparisons of the independent variables. These discrepancies were covered previously (Kritzer Van Zant, 2016a; Kritzer Van Zant et al., 2018, 2019) and summarized in the Supporting Information (SI) for this paper. SI also included consideration of the exploratory results which were not applied to the three hypotheses, and included discussion of results for interaction terms produced in some of the ANOVAs. In addition, though positive results are given in the main text of this paper, arranged for each indispensable and dispensable amino acid, CRDP and TOTP, they are reconsidered, arranged for each independent variable, in the SI. Detail for some positive results summarized in the main text are therefore only given in SI.

Results were extensive. Therefore, though positive results are presented in the text, tables for all statistical results for all amino acids, including positive and negative results, are currently only available in Appendix C-7 Of Kritzer Van Zant's (2016a) dissertation (Extended (EXT) Tables 1-20). From herein in this paper and in its SI, all extended tables from Appendix C-7 (Kritzer Van Zant 2016a) are only identified by the abbreviated 'EXT Table(s)' designation, without repeating their source.

LYS was singled out for summary data tables included in this paper (Tables 1 and 2), because LYS is the consensus indispensable amino acid used as an indicator of protein quality, and of special importance for vegetarian diets (Reeds, 2000; WHO, 2007; Woolf et al., 2011). CRDP (Tables 3 and 4) and TOTP (Tables 5 and 6 ) were also presented in summary tables in the body of the paper, because percentages by weight of each were outstanding in $M$. expansa, particularly for leaves, relative to other protein sources examined (Kritzer Van Zant et al., 2019). Percentages of most individual amino acids found in $M$. expansa were competitive with those in other protein sources to which they were compared, including all ten indispensable amino acids (Kritzer Van Zant, 2016a; Kritzer Van Zant, 2019). Hypotheses and levels of variables are detailed in Materials and Methods below.

Information on the growth of $M$. expansa in southern Illinois, used for this research, was detailed previously (Kritzer Van Zant et al., 2018), as well as summarized later (SI). M. expansa's amino acid profiles were also previously presented (Kritzer Van Zant et al., 2019). Introductory information used previously (Kritzer Van Zant, 2016a, b, 2017; Kritzer Van Zant et al., 2018, 2019) also applies to the analyses in this paper. Earlier publications summarized information on $M$. expansa from the Latin American literature (Kritzer Van Zant, 2016a, 2017), and the history of use and biochemical research on the family Nyctaginaceae (Kritzer Van Zant, 2016a, b). Recent papers on Mirabilis included research on peptides derived from M. jalapa $\mathrm{L}$. for their potential as biopesticides (Maulina et al., 2018), an update on ongoing agronomic and other research on M. expansa in the Andes (Seminario et al., 2019), and information from a recent study of the current status of $M$. expansa amongst indigenous farmers, and attempts to revive interest in consuming and growing $M$. expansa, primarily in Peru (Gendall et al. 2019).

\section{Materials and Methods}

Plants used for the amino acid profiles were grown in southern Illinois, lyophilized, and submitted for amino acid profiling (Horwitz and Latimer, 2006, 2011; Kritzer Van Zant, 2016a; Kritzer Van Zant et al., 2018, 2019). Plant structure above vs below ground, and soil amendments in which those plants were grown (Kritzer Van Zant, 2016a; Kritzer Van Zant et al., 2018), were examined for their potential effect on the percentages of amino acids produced in M. expansa (Kritzer Van Zant, 2016a; Kritzer Van Zant et al., 2019). Plots used to grow this material were at least $95 \%$ sand. Percentages of soil amendments in these plots were utilized as levels of independent variables for statistical purposes. In addition, structures grown above vs. below ground were levels for the independent variable structure.

Percentages of LYS, CRDP and TOTP (Tables 1-6) and other profiled M. expansa amino acids (EXT Tables 1-20) are the results from statistical analyses in ANOVAs and Tukey adjusted LS-Means. These analyses were performed in SAS 9.3 (SAS Institute Inc., Cary, NC), to examine relationships between quantities of amino acids produced and the percentages of peat and steer manure added to the sand plots used to grow the plants, at the time of their construction. Results of the analyses were interpreted relative to each applicable hypothesis in the main text. All results were presented for all indispensable and dispensable amino acids assayed, and for both CRDP and TOTP, in EXT Tables 1-20 in Appendix C-7 (Kritzer Van Zant 2016a). Positive results that were not used to resolve the hypotheses are in the SI for this paper.

Plants grew as masses of vines, and stored starch and protein in enlarged roots, stems, and underground rhizomes. Once engorged with starch, vascular arrangements of these structures became obscured and difficult to distinguish even in slides of cross-sections under magnification. In addition, the primary storage area in M. expansa for starch, is the crown of the plant where these structures meet just below the soil line. It was difficult to see what portions of the crown are truly roots, rhizomes, or the base of emerging stems. For these reasons, plant structure was separated based on growth above versus below ground for statistical purposes.

EXT ANOVA Tables 1-3 and EXT LS-Means Tables 11-13, all contained data for the pair-wise comparison of the variables structure and variety. In EXT Tables 1 and 11, data for var. ' $T$ ' grown in the greenhouse, separately for leaf and stem, were included in the analyses of data from field-grown material. In EXT Tables 2 and 12, the var. ' $T$ ' greenhouse-grown leaf data 
was included while the var. ' $T$ ' greenhouse-grown stem data was excluded. In EXT Tables 3 and 13, neither leaf nor stem data for var. ' $T$ ' grown in the greenhouse was included. The only differences among the results described within these two sets each of three tables, were those to be expected as a result of the inclusion or exclusion of more categories of data. Therefore, of the six versions of the analyses of structure x variety, only data from EXT Tables 1 and 11 were actually considered in the main paper, as they are the most complete of each set. All six of these EXT tables were referred to by their separate table numbers so the differences among the data they contain could be addressed in the discussion.

Additionally, data tables from analyses of pair-wise comparisons that resulted in no significant data retained consecutive table numbers in the text of Kritzer Van Zant's dissertation (2016a) though they were not presented in table form and only briefly mentioned in that text (Kritzer Van Zant 2016a). This kept the relative numbering system intact for the same pairs of independent variables, which remains intact in this paper and its SI. For example, ANOVA EXT Table 2 contains data for the same pair of independent variables as LS-Means EXT Table 12, ANOVA EXT Table 6 is for the same pair-wise comparison as LS-Means EXT Table 16, etc. This was done to avoid confusion over missing tables and analyses due to the lack of results. Some tables had significant results from ANOVAs which had no correlating positive or computable results in the matching LS-Means analyses, and visa-versa (Kritzer Van Zant 2016a). Using table numbers in the text (Kritzer Van Zant 2016a), that matched with extended table numbers in the description also kept table numbers consistent with graphs of the ANOVAs for the same pair-wise analyses, given as Figures 1-1000 in Appendix C-8 of Kritzer Van Zant's dissertation (2016a). Therefore, numbering for those graphs can also be matched to the data from the EXT tables referenced in this paper and SI.

Raw percentage data from the amino acid profiles were also given previously (Kritzer Van Zant et al., 2019) in the form of tables, and the data in those tables later used for each pair-wise comparison in the EXT tables (Kritzer Van Zant 2016a). In the main text of this paper, ANOVA (Tables 1, 3,5) and LS-Means (Tables 2, 4, 6) combination tables have positive results from all statistical analyses summarized for LYS (Tables 1, 2), CRDP (Tables 3, 4) and TOTP (Tables 5, 6).

Positive LS-Means results were also extensive, so only text descriptions of positive Tukey-adjusted LS-Means results are given in this paper and SI. Levels of LS-Means results are arranged from least to most significant for each amino acid.

Only ANOVA results that were significant or approaching significance for at least one of the hypotheses, at the .05 level of probability or less, are presented in the main text. Each independent variable applicable to any of the hypotheses, was first addressed through each pair-wise comparison in ANOVAs that included it, for analyses both with and without the interaction term request. Next, the same independent variable was examined in each LS-Means analyses which included it, described in greater detail in the SI for this paper. Positive results of analyses were presented separately and consecutively from the EXT tables for each amino acid, CRDP or TOTP. This process was continued until every independent variable had been considered for every pair-wise comparison in which it was included. Results were discussed in the main text, arranged by amino acid, CRDP or TOTP. Discussion of the same results, arranged by independent variable, are in the SI, though the data itself was not repeated. Variety and COA were analyzed in the same way as other independent variables (SI), though neither addressed any hypothesis. Statistical principles discourage setting up hypothesis after applicable analyses have been run. Variety and COA had already been included in earlier analyses with each variety run separately to address the hypotheses. Additionally, COA plots had been considered separately for their peat and steer manure percentages to address the hypotheses. Later a decision was made to run exploratory analyses that treated both varieties at the same time in spite of their discrepancies, and separately, to run analyses that kept COA plots distinct and also included data from all plots containing peat or steer manure by themselves. Interaction results from ANOVAs that included an interaction term request were also discussed separately (SI).

\section{Hypotheses for Amino Acid Profiling}

Three hypotheses were established prior to running the ANOVAs and LS-Means analyses on the amino acid profiles data. Below ground structures were labeled roots, and above ground material labeled shoots, for purposes of the hypotheses, for reasons explained in the above Introduction. Shoots included leaves for var. ' $L$ ' and leaf and stem separately for var. ' $T$ ' (SI).

First is the structure hypothesis: $\mathrm{H}_{0}=$ There will not be a significant difference in quantity for each amino acid, between above and below ground plant parts; and $\mathrm{H}_{1}=$ There will be a significant difference in quantity for each amino acid, between above and below ground plant parts.

Second is the peat hypothesis: $\mathrm{H}_{0}=$ Amount of peat added at the time of plot construction, has no effect on the amount of amino acid produced, considered individually, in roots and separately in shoots; and $\mathrm{H}_{1}=$ Amount of peat added at the time of plot construction has an effect on the amount of amino acid produced, considered individually, in roots and separately in shoots.

Third is the steer manure hypothesis: $\mathrm{H}_{0}=$ Amount of steer manure added at the time of plot construction has no effect on the amount of amino acid produced, considered individually, in roots and separately in shoots; and $\mathrm{H}_{1}=$ Amount of steer manure added at the time of plot construction has an effect on the amount of amino acid produced, considered individually, in roots and separately in shoots.

Percentages of individual amino acids, CRDP and TOTP, in the ANOVAs and LS-Means analyses, supported $\mathrm{H}_{0}$ if not significant and $\mathrm{H}_{1}$ if significant, in applicable hypotheses.

Interpretation of these analyses was limited by discrepancies within the raw data (Kritzer Van Zant, 2016a, b, 2017; Kritzer Van Zant et al. 2018, 2019), summarized in the SI. Conflicting results among pair-wise analyses, for the same independent variables, were also problematic for resolving the hypotheses, despite considerable amounts of significance. Some of this may 
have been due to conflicts in the raw data. All discussion of analyses for structure, peat or steer manure paired with variety or COA (Combined Organic Amendments), or plots containing both peat and steer manure, are also in the SI.

Results from the analyses held contradictions for each independent variable. Therefore, it became necessary to consider each independent variable separately across all analyses instead of considering each set of pair-wise analyses separately. The summary tables of results from each of the ANOVA (Tables 1, 3,5 ) and LS-Means analyses (Tables 2, 4, 6) for LYS (Tables 1, 2), CRDP (Tables 3, 4) and TOTP (Tables 5, 6) showed the method of breakdown of data for each independent variable, and included only positive results, if any, from each set of pairwise analyses. However, percentages of peat and steer manure in COA plots, were each separately included in the peat only and steer manure only analyses paired with other independent variables. Ignoring that the $1 \%$ peat or $3 \%$ steer manure data came from plots that contained both, in the peat only or steer manure only analyses, for some raw data may have skewed results. However, this effect appeared minimal when the results of the individual analyses for peat and steer manure were considered against each other and against the results of the exploratory COA analyses (SI). Examination of the figures in Appendix C-8 (Kritzer Van Zant 2016a) that accompany the extended tables of the ANOVA results, can assist with understanding the role that $1 \%$ peat and $3 \%$ steer manure data, which came from plots that contained both, had on the overall results.

\section{Amino Acids}

Twenty-three amino acids, CRDP and TOTP, were the dependent variables in the ANOVAs (EXT Tables 1-10) and Tukey-adjusted LS-Means (EXT Tables 11-20) analyses. All amino acid profiling results were given as percent dry weight per $100 \mathrm{~g}$ of sample in all tables referenced in this paper and the EXT tables from which they were summarized. All ten indispensable amino acids were profiled and statistically analyzed - arginine (ARG), histidine (HIS), isoleucine (ISO), leucine (LEU), lysine (LYS), methionine (MET), phenylalanine (PHE), threonine (THR), tryptophan (TRP) and valine (VAL). Thirteen dispensable amino acids were also profiled and statistically analyzed - alanine (ALA), aspartic acid (ASP), cysteine (CYS), glutamic acid (GLU), glycine (GLY), hydroxyproline (HPR), hydroxylysine (HLY), lanthionine (LAN), ornithine (ORN), proline (PRO), serine (SER), taurine (TAU) and tyrosine (TYR). These abbreviations were used in the remaining text, tables (1-6), EXT Tables 1-20, and in SI for this paper.

CRDP is a measure of the percentage of all nitrogen containing compounds in each sample. TOTP measures the percentage of nitrogen in samples of only amino acids. Some TOTP was lost as is typical during the hydrolysis step of the percent amino acid assays. Percentages of amino acids per CRDP have been presented by some authors (Zarkadas, 1997; House et al., 2010). A table was given previously with percent amino acids/ CRDP for $M$. expansa (Kritzer Van Zant et al., 2019). CRDP and TOTP were each only considered separately here.

\section{Statistical Data Analysis}

Each data point represented more than one plant from more than one plot which received the same percentage of a soil amendment, or more than one cloned individual grown exclusively in the greenhouse. Var. ' $\mathrm{T}$ ' data was only statistically analyzed in pair-wise comparisons that included variety as an independent variable (SI).

ANOVA and Tukey-adjusted LS-Means p-values were considered significant at $5 \%$ or less. Independent variables were analyzed in pairs in ANOVAs, without and with requests for interaction terms, separately for the same data, which usually altered the degrees of freedom and therefore modified some of the significance in the ANOVA results.

ANOVA results for each dependent variable were first compared without and with the interaction term request, then compared to ANOVAs for the same dependent variable in analyses in which they were paired with other independent variables, and lastly comparison was made with Tukey-adjusted LS-Means results for the same pairs of independent variables. This was done to reduce the effect of the imbalances in the data. Interactions could only be considered for pairs of variables separately, due to the small size of data sets, and were also discussed separately to reduce repetition (SI).

Tukey adjusted LS-Means analyses examined relationships among pairs of levels for each pair-wise comparison of independent variables. LS-Means results (Tables 2,4,6; EXT Tables 1120) were reported with standard errors, degree of significance, and accompanying Tukey-Kramer letters, if generated. TukeyKramer letter assignments indicate proximity of the means to each other for each pair-wise comparison of levels of independent variables, and were computed separately, if at all, for each amino acid, CRDP and TOTP. LS Means with the same letter assignment in the EXT tables (Kritzer Van Zant 2016a), were not significantly different from each other for different variable and level combinations. Tukey-Kramer letters were computed separately for each amino acid, CRDP and TOTP.

In Tables 1-6, ANOVA and LS-Means EXT tables 1-20, and in the LS-Means results detailed in SI, asterisks indicated the degree of significance (Kritzer Van Zant 2016a). If an asterisk was lacking, there was no significant result. One asterisk indicated a probability of $.05 \%$ or less, and was described in the text as significant. Two asterisks indicated a probability equal to or less than $.0001 \%$ which was described in the text as highly significant.

Results were presented to two digits after the decimal. Though numbers six through nine were rounded up, the number 5 was rounded down. This made a slight reduction in the ANOVA and LS-means results values as well as in the error term, compared with rounding five up. Some noise dropped out of the results of the analyses because of this rounding change. Despite limitations, statistics gave insight into which of the independent variables appear to have influenced quantities of certain individual amino acids, and which clearly did not. 


\section{Results and Discussion}

Imperfect sample matches created imbalances in the data. Despite these imbalances, some rough comparisons in the ANOVAs were still possible that otherwise would have been more difficult to consider. In addition, it was possible to make sense of some relative values in the LS-Means analyses that were not resolved in the ANOVAs.

Positive results are presented from the ANOVAs of the pairwise comparisons of the independent variables for structure $\mathrm{x}$ variety with greenhouse leaf and stem data for var. ' $T$ ' (EXT Table 1; SI 2.1-2.11), variety by steer manure (EXT Table 6), structure x COA (EXT Table 7), structure x peat (EXT Table 8), and structure $\mathrm{x}$ steer manure (EXT Table 9). Tukey adjusted LS-Means pair-wise analyses of independent variables resulted in significant results from structure $\mathrm{x}$ variety with greenhouse leaf and stem data for var. ' $T$ ' (EXT Table 11), variety x COA (EXT Table 14; see SI 3.6), variety x peat (EXT Table 15; see SI 3.6 and Tables 2 and 4), variety x steer manure (EXT Table 16; see SI 3.6 and Tables 2 and 4), structure x peat (EXT Table 18; see results in SI 3.3 and Tables 2, 4 and 6), structure x steer manure (EXT Table 19; see SI 3.4 and Tables 2, 4 and 6), and peat $\mathrm{x}$ steer manure (EXT Table 20). Details of positive LS-means results for various level combinations were given previously in Tables 2, 4, and 6 in the main text, as well as in SI 3.2. Also in SI are discussions of the differences between ANOVA EXT Table 1, vs ANOVA EXT Tables 2 and 3, and LS-Means EXT Table 11 vs EXT Tables 12 and 13 (SI 2.1-2.11, 3.1 and 3.8,

Amino acid abbreviation: LYS = indispensable lysine. interaction requested; $\mathrm{IndpV}=$ Independent variable. indicates high significance at the .0001 or less level of probability. and in the main text Tables 2, 4 and 6), all six EXT tables contained data from structure $\mathrm{x}$ variety pair-wise comparisons. EXT Tables 1 and 11 had all of the field data for structure for both varieties, and all of the greenhouse data for var. ' $T$ '. EXT Tables 2, 3,12 , and 13 , all contained results from different versions of the structure $\mathrm{x}$ variety analyses (SI 2.1-2.11). No greenhouse leaf data for var. ' $T$ ' was included though stem data for var. ' $T$ ' was included for EXT Tables 2 and 12. EXT Tables 3 and 13 results had no greenhouse data included for var. ' $T$ ' leaf or stem.

ANOVAs variety x COA (EXT Table 4), variety x peat (EXT Table 5), and peat $x$ steer manure (EXT Table 10), had no significant results for any amino acid, CRDP or TOTP. Only Tukey adjusted LS-Means analyses structure x COA (EXT Table 17; see SI 3.6) lacked any significant results for any amino acid, CRDP, TOTP, among the combinations of their levels. Analyzing each pair of variables with and without an interaction term request for the ANOVAs, changed the resulting degrees of freedom and error terms for models, and in some cases for individual independent variables as components of those models.

Tables that included structure as an independent variable (EXT Tables 1- 3, 7- 9, 11- 13, 17-19) included leaf (above ground) and root (below ground) as levels for both varieties, and stem (above ground) as a level only for var. ' $T$ '. Tables also included results for percentages of steer manure (EXT Tables 6, 9, 16, 19), and peat (EXT Tables 5, 8, 10, 15, 18, 20). Peat x steer manure were also separately examined (EXT Tables 10 and 20) and those results also considered below. As there were many positive results, often in conflict for interpreting the hypotheses,

Table 1. Lysine, combined results from ANOVAs for M. expansa.

\begin{tabular}{|c|c|c|c|c|c|c|}
\hline I or none & IndpV & DepV & F Value & $\mathbf{d f}_{1}, \mathbf{d f}_{\mathbf{2}}$ & $\begin{array}{l}\text { p-value }= \\
\text { Pr }>\text { F for } \\
\text { ANOVA }\end{array}$ & $\begin{array}{l}\text { p-value } \\
\text { significance } \\
\text { at .05 level }\end{array}$ \\
\hline \multicolumn{7}{|c|}{ EXT TABLE 1: Structure $\mathrm{x}$ variety with greenhouse leaf and stem data for var. ' $T$ ': } \\
\hline & strc & LYS & 243.28 & 2,8 & $<.0001$ & $* *$ \\
\hline I & strc & LYS & 552.51 & 2,7 & $<.0001$ & $* *$ \\
\hline I & $\mathrm{v}$ & LYS & 5.74 & 1,7 & 0.0477 & $*$ \\
\hline \multicolumn{7}{|c|}{ EXT TABLE 2: Structur } \\
\hline & strc & LYS & 475.07 & 1,8 & $<.0001$ & $* *$ \\
\hline I & strc & LYS & 1087.67 & 1,7 & $<.0001$ & $* *$ \\
\hline I & $\mathrm{v}$ & LYS & 5.74 & 1,7 & 0.0477 & $*$ \\
\hline I & $\mathrm{strc} * \mathrm{v}$ & LYS & 20.93 & 1,7 & 0.0026 & $*$ \\
\hline \multicolumn{7}{|c|}{ EXT TABLE 3: Structure $\mathrm{x}$ variety with no greenhouse data for var. ' $T$ ' } \\
\hline & strc & LYS & 1410.33 & 1,7 & $<.0001$ & $* *$ \\
\hline I & strc & LYS & 1410.33 & 1,7 & $<.0001$ & $* *$ \\
\hline \multicolumn{7}{|c|}{ EXT TABLE 4: Variety x COA - no positive results } \\
\hline \multicolumn{7}{|c|}{ EXT TABLE 5: Variety $x$ peat - no positive results } \\
\hline \multicolumn{7}{|c|}{ EXT TABLE 6: Variety $\mathrm{x}$ steer manure - only dispensable HLY had positive results } \\
\hline \multicolumn{7}{|c|}{ EXT TABLE 7: Structure x COA: } \\
\hline & strc & LYS & 2980.12 & 1,3 & $<.0001$ & $* *$ \\
\hline \multicolumn{7}{|c|}{ EXT TABLE 8: Structure $\mathrm{x}$ peat: } \\
\hline & strc & LYS & 2602.27 & 1,5 & $<.0001$ & $* *$ \\
\hline I & strc & LYS & 2221.78 & 1,3 & $<.0001$ & $* *$ \\
\hline \multicolumn{7}{|c|}{ EXT TABLE 9: Structure x steer manure: } \\
\hline & strc & LYS & 758.89 & 1,5 & $<.0001$ & $* *$ \\
\hline I & strc & LYS & 540.08 & 1,3 & 0.0002 & $*$ \\
\hline
\end{tabular}

Abbre viations for inde pendent variables and levels: $\mathrm{COA}=$ combined organic amendments $=$ peat plots and steer manure plots and plots containing both; $s$ re $=$ structure $=$ plant part; $\mathrm{v}=$ variety; $\operatorname{str}^{*} \mathrm{v}=$ interaction

Other abbre viations: $\mathrm{DepV}=$ Dependent variable; $\mathrm{df}_{2}=$ error; $\mathrm{I}=$ Interaction requested vs none $=$ blank space $=$ no

Key to symbols: One asterisk $(*)$ indicates significance at the .05 to 0.001 level of probability; Two asterisks $(* *)$ 
Table 2. Lysine, combined results from Tukey adjusted LS-Means for M. expansa.

\begin{tabular}{|c|c|c|c|}
\hline $\begin{array}{l}\text { LYS } \\
\text { Means }\end{array}$ & Structure & Var. ' $L$ ' LS Means & Var. ' $T$ ' LS \\
\hline \multicolumn{4}{|c|}{ EXT TABLE 11: Structure $\mathrm{x}$ variety with greenhouse leaf and stem data for var. ' $T$ ': } \\
\hline LYS & leaf & $1.45 \pm 0.02_{\mathrm{A}} * *$ & $1.25 \pm 0.04_{\mathrm{B}} * *$ \\
\hline LYS & root & $0.37 \pm 0.02_{\mathrm{C}} * *$ & $0.43 \pm 0.03_{\mathrm{C}} * *$ \\
\hline LYS & stem & & $0.41 \pm 0.04_{C} * *$ \\
\hline \multicolumn{4}{|c|}{ EXT TABLE 12: Structure $x$ variety with greenhouse leaf data not including stem for var. ' $T$ ' } \\
\hline LYS & leaf & $1.45 \pm 0.02_{\mathrm{A}} * *$ & $1.25 \pm 0.04_{\mathrm{B}} * *$ \\
\hline LYS & root & $0.37 \pm 0.02_{\mathrm{C}} * *$ & $0.43 \pm 0.03_{\mathrm{C}} * *$ \\
\hline \multicolumn{4}{|c|}{ EXT TABLE 13: Structure $\mathrm{x}$ variety with no greenhouse data for var. ' $T$ ': } \\
\hline LYS & leaf & $1.45 \pm 0.02_{\mathrm{A}} * *$ & \\
\hline LYS & root & $0.37 \pm 0.02_{\mathrm{B}} * *$ & $0.43 \pm 0.03_{\mathrm{B}} * *$ \\
\hline \multicolumn{4}{|c|}{ EXT TABLE 14: Variety x COA -no positive results for lysine } \\
\hline \multicolumn{4}{|c|}{ EXT TABLE 15 : Variety x peat: } \\
\hline LYS & control & $0.91 \pm 0.34_{A} *$ & $0.38 \pm 0.68_{\mathrm{A}}$ \\
\hline LYS & $\mathrm{P}$ & $0.92 \pm 0.48_{\mathrm{A}}$ & \\
\hline LYS & PP & & $0.49 \pm 0.68_{\mathrm{A}}$ \\
\hline LYS & PPP & $0.90 \pm 0.48_{\mathrm{A}}$ & \\
\hline \multicolumn{4}{|c|}{ EXT TABLE 16: Variety x steer manure: } \\
\hline LYS & control & $0.89 \pm 0.34_{\mathrm{A}} *$ & $0.49 \pm 0.68_{\mathrm{A}}$ \\
\hline LYS & SSS & $0.92 \pm 0.48_{\mathrm{A}}$ & \\
\hline LYS & SSSS & & $0.38 \pm 0.68_{\mathrm{A}}$ \\
\hline LYS & SSSSS & $0.93 \pm 0.48_{\mathrm{A}}$ & \\
\hline \multicolumn{4}{|c|}{ EXT TABLE 17: Structure x COA - no positive results } \\
\hline \multicolumn{4}{|c|}{ EXT TABLE 18: Structure $\mathrm{x}$ peat: } \\
\hline LYS & control & $1.46 \pm 0.02_{\mathrm{A}} * *$ & $0.37 \pm 0.02_{\mathrm{B}} *$ \\
\hline LYS & $\mathrm{P}$ & $1.47 \pm 0.03_{\mathrm{A}} * *$ & $0.38 \pm 0.03_{\mathrm{B}} *$ \\
\hline LYS & PP & & $0.49 \pm 0.03_{\mathrm{B}} *$ \\
\hline LYS & PPP & $1.41 \pm 0.03_{\mathrm{A}} * *$ & $0.39 \pm 0.03_{\mathrm{B}} *$ \\
\hline \multicolumn{4}{|c|}{ EXT TABLE 19: Structure $x$ steer manure: } \\
\hline LYS & control & $1.42 \pm 0.04_{\mathrm{A}} * *$ & $0.41 \pm 0.04_{\mathrm{B}} *$ \\
\hline LYS & SSS & $1.47 \pm 0.06_{\mathrm{A}} *$ & $0.38 \pm 0.06_{\mathrm{B}} *$ \\
\hline LYS & SSSS & & $0.38 \pm 0.06_{\mathrm{B}} *$ \\
\hline LYS & SSSSS & $1.49 \pm 0.06_{\mathrm{A}} *$ & $0.38 \pm 0.06_{\mathrm{B}} *$ \\
\hline
\end{tabular}

Notes: Tukey adjusted LS Means include SDs among levels of independent variables for LYS, letters showing similar Tukey adjusted LS Means, and asterisks indicating degrees of significance; leaf and root were levels of structure forboth varieties.

Abbre viations for inde pendent variables and their le vels: $\mathrm{COA}=$ combined organic amendments $=$ peat plots and steer manure plots and plots containing both; control = all sand; steerM = steer manure; $\mathrm{P}=1 \%$ peat ( PSSS plots) $\mathrm{PP}=2 \%$ peat $; \mathrm{PPP}=3 \%$ peat $; \mathrm{PSSS}=1 \%$ peat with $3 \%$ steerM in the same plot; SSS $=3 \%$ steerM (same as PSSS plots); SSSS $=4 \%$ steerM; SSSSS $=5 \%$ steerM; varieties ' $L$ ' and ' $T$ were levels of variety. Amino acid abbreviation: $\mathrm{LYS}=$ lysine.

O ther abbreviations: EXT $=$ Extended T able(s) from Appendix C-7 of Kritzer Van Zant's (2016a) dissertation. Key to symbols: One asterisk $(*)$ indicates significance at the .05 to 0.001 level of probability; T wo asterisks $\left({ }^{* *}\right)$ indicat es high significance at the .0001 or less level of probability. No asterisk means no significance.

results and discussion of all pair-wise comparison analyses having variety and/or COA as independent variables, are also only discussed in SI.

Other pairs of independent variables discussed in the main text below were structure $\mathrm{x}$ peat (EXT Tables 8, 18), structure $\mathrm{x}$ steer manure (EXT Tables 9, 19), and peat x steer manure (EXT Tables 10, 20). Variable levels for these analyses were for structure, leaf with some fine stem material for both varieties, root for both varieties, and from the greenhouse material stem without leaves only for var. ' $T$ '. For peat considered alone variable levels were $0 \%$ peat for each variety, $1 \%$ peat from the same plots as $3 \%$ steer manure only for var. ' $L$ ', $2 \%$ peat only for var. ' $T$ ', and $3 \%$ peat only for var. ' $L$ '. For steer manure considered alone variable levels were $0 \%$ steer manure only for var. ' $L$ ', $3 \%$ steer manure from the same plots as $1 \%$ peat only for var. ' $L$ ', $4 \%$ steer manure only for var. ' $T$ ', and $5 \%$ steer manure only for var. ' $L$ '. Therefore, a single variable level, along each of the continuums for percentages of peat and steer manure, additionally had some of the other soil amendment, which were also separately analyzed as the COA plots for var. ' $L$ '. Despite these short comings, in varieties ' $L$ ' and ' $T$ ' grown outdoors for a single temperate summer in southern Illinois, lack of variation between the variable levels still indicates that the amounts of particular amino acids were intrinsic to the varieties and structures of the plants. In addition, it was show that under the given conditions, relative quantities of some amino acids were either affected or not by variation in quantities of peat and steer manure. Though discussion below includes some of the information from the LS-Means extended tables (Kritzer Van Zant 2016a), the details of often lengthy positive results from these LS-Means EXT tables are in SI unless given in the summary tables in the main text. 
Table 3. Crude protein, combined results from ANOVAs for M. expansa.

\begin{tabular}{|c|c|c|c|c|c|c|}
\hline I or none & IndpV & DepV & F Value & $\mathbf{d f}_{1}, \mathbf{d f}_{\mathbf{2}}$ & $\begin{array}{l}\text { p-value }= \\
\text { Pr }>\text { F for } \\
\text { ANOVA }\end{array}$ & $\begin{array}{l}\text { p-value } \\
\text { significance } \\
\text { at } .05 \text { level }\end{array}$ \\
\hline \multicolumn{7}{|c|}{ EXT TABLE } \\
\hline & strc & CRDP & 60.12 & 2,8 & $<.0001$ & $* *$ \\
\hline I & strc & CRDP & 110.12 & 2,7 & $<.0001$ & $* *$ \\
\hline I & $\mathrm{strc}^{*} \mathrm{v}$ & CRDP & 18.97 & 1,7 & 0.0033 & * \\
\hline \multicolumn{7}{|c|}{ EXT TABLE 2: Structure $x$ variety with greenhouse leaf data not including stem for var. } \\
\hline & strc & CRDP & 116.24 & 1,8 & $<.0001$ & $* *$ \\
\hline I & strc & CRDP & 214.48 & 1,7 & $<.0001$ & $* *$ \\
\hline I & $\mathrm{strc}^{*} \mathrm{v}$ & CRDP & 18.97 & 1,7 & 0.0033 & * \\
\hline \multicolumn{7}{|c|}{ EXT TABLE 3: Structure $\mathrm{x}$ variety with no greenhouse data for var. ' $T$ ': } \\
\hline & strc & CRDP & 361.02 & 1,7 & $<.0001$ & $* *$ \\
\hline I & strc & CRDP & 361.02 & 1,7 & $<.0001$ & $* *$ \\
\hline \multicolumn{7}{|c|}{ EXT TABLE 4: Variety x COA - no positive results } \\
\hline \multicolumn{7}{|c|}{ EXT TABLE 5: Variety x peat-no positive results } \\
\hline \multicolumn{7}{|c|}{ EXT TABLE 6: Variety $x$ steer manure - only dispensable HLY had positive results } \\
\hline \multicolumn{7}{|c|}{ EXT TABLE 7: Structure x COA: } \\
\hline & strc & CRDP & 2049.44 & 1,3 & $<.0001$ & ** \\
\hline & $\mathrm{COA}$ & CRDP & 11.54 & 5,3 & 0.0357 & * \\
\hline \multicolumn{7}{|c|}{ EXT TABLE 8: Structure x peat: } \\
\hline & strc & CRDP & 1224.83 & 1,5 & $<.0001$ & $* *$ \\
\hline & peat & CRDP & 9.34 & 3,5 & 0.0171 & * \\
\hline I & strc & CRDP & 817.39 & 1,3 & $<.0001$ & $* *$ \\
\hline \multicolumn{7}{|c|}{ EXT TABLE 9: Structure x steer manure: } \\
\hline & strc & CRDP & 175.15 & 1,5 & $<.0001$ & $* *$ \\
\hline I & strc & CRDP & 111.92 & 1,3 & 0.0018 & * \\
\hline
\end{tabular}

\footnotetext{
Abbreviations for independent variables: $\mathrm{COA}=$ combined organic amendments $=$ peat plots and steer manure plots and plots containing both; $s$ trc $=$ structure $=$ plant part; $\mathrm{v}=$ variety; $\operatorname{str}^{*} \mathrm{v}=$ interaction

Amino acid abbreviation: $\mathrm{CRDP}=$ crude protein .

O ther abbrevi ations: DepV $=$ Dependent variable; $\mathrm{df}_{2}=$ error; $\mathrm{EXT}=$ Extended T able(s) from Appendix C-7 of Kritzer

Van Zant's (2016a) dissertation; I = Interaction requested vs none= blank space $=$ no interaction requested; IndpV= Independent variable.

Key to symbols: One asterisk (*) indicates significance at the .05 to 0.001 level of probability; Two asterisks $(* *)$ indicates high significance at the .0001 or less level of probability. No asterisk means no significance.
}

\section{Positive Results for structure in the structure $x$ peat ANO- VAs with no greenhouse data for var. ' $T$ '}

Positive results for structure for the indispensable amino acids and totals in the ANOVAs for the independent variables of structure $\mathrm{x}$ peat with no greenhouse data for var. ' $T$ ' (EXT Table 8 ) without the interaction term request were all highly significant for: ARG $\left(\mathrm{F}=2441.55_{1,5}, \mathrm{p}=<.0001\right)$, HIS $\left(\mathrm{F}=2425.50_{1,5}, \mathrm{p}=\right.$ $<.0001)$, ISO $\left(\mathrm{F}=1798.83_{1,5}, \mathrm{p}=<.0001\right)$, LEU $\left(\mathrm{F}=2492.58_{1,5}\right.$, $\mathrm{p}=<.0001), \operatorname{LYS}\left(\mathrm{F}=2602.27_{1,5}, \mathrm{p}=<.0001\right), \operatorname{MET}(\mathrm{F}=$ $\left.1834.10_{1,5}, \mathrm{p}=<.0001\right), \operatorname{PHE}\left(\mathrm{F}=2617.63_{1,5}, \mathrm{p}=<.0001\right), \mathrm{THR}$ $\left(\mathrm{F}=1395.09_{1,5}, \mathrm{p}=<.0001\right), \mathrm{TRP}\left(\mathrm{F}=938.94_{1,5}, \mathrm{p}=<.0001\right)$, $\operatorname{VAL}\left(\mathrm{F}=1940.43_{1,5}, \mathrm{p}=<.0001\right), \operatorname{CRDP}\left(\mathrm{F}=1224.83_{1,5}, \mathrm{p}=\right.$ $<.0001)$, and TOTP $\left(\mathrm{F}=2943.52_{1,5}, \mathrm{p}=<.0001\right)$.

Positive results for structure for the indispensable amino acids and totals in the ANOVAs for the independent variables of structure $x$ peat with no greenhouse data for var. ' $T$ ' (EXT Table 8 ) with the interaction term request were all highly significant for: $\operatorname{ARG}\left(\mathrm{F}=2575.74_{1,3}, \mathrm{p}=<.0001\right)$, HIS $\left(\mathrm{F}=2463.52_{1,3}, \mathrm{p}=\right.$ $<.0001)$, ISO $\left(\mathrm{F}=2652.12_{1,3}, \mathrm{p}=<.0001\right)$, LEU $\left(\mathrm{F}=3168.40_{1,3}\right.$, $\mathrm{p}=<.0001), \operatorname{LYS}\left(\mathrm{F}=2221.78_{1,3}, \mathrm{p}=<.0001\right), \operatorname{MET}(\mathrm{F}=$ $\left.16274.80_{1,3}, \mathrm{p}=<.0001\right), \operatorname{PHE}\left(\mathrm{F}=7220.70_{1,3}, \mathrm{p}=<.0001\right)$, THR $\left(\mathrm{F}=2468.52_{1,3}, \mathrm{p}=<.0001\right), \mathrm{TRP}\left(\mathrm{F}=1368.10_{1,3}, \mathrm{p}=<.0001\right)$, $\operatorname{VAL}\left(\mathrm{F}=1978.72_{1,3}, \mathrm{p}=<.0001\right), \operatorname{CRDP}\left(\mathrm{F}=817.39_{1,3}, \mathrm{p}=\right.$ $<.0001)$, and TOTP $\left(\mathrm{F}=4841.27_{1,3}, \mathrm{p}=<.0001\right)$.

Therefore, for structure in the ANOVAs for structure $\mathrm{x}$ peat (EXT Table 8) without and with the interaction term request, all ten indispensable amino acids and both CRDP and TOTP, were significant or highly significant in full agreement with $\mathrm{H}_{1}$ in the structure hypothesis.

\section{Positive Results for Peat in the Structure $x$ Peat ANOVAs with no Greenhouse Data for var. ' $T$ '}

Positive results for peat for the indispensable amino acids and totals in the ANOVAs for the independent variables of structure $x$ peat with no greenhouse data for var. ' $T$ ' (EXT Table 8) without the interaction term request was significant for HIS $\left(\mathrm{F}=9.34_{3,5}, \mathrm{p}=0.0172\right), \mathrm{CRDP}\left(\mathrm{F}=9.34_{3,5}, \mathrm{p}=0.0171\right)$, and TOTP $\left(\mathrm{F}=05.49_{3,5}, \mathrm{p}=0.0487\right)$.

Positive results for peat for indispensable amino acids and totals in the ANOVAs for independent variables structure $\mathrm{x}$ peat 
with no greenhouse data for var. ' $T$ ' (EXT Table 8) with the interaction term request was significant for HIS ( $\mathrm{F}=10.94_{3,3}$, $\mathrm{p}=0.0401), \operatorname{MET}\left(\mathrm{F}=30.53_{3,3}, \mathrm{p}=0.0095\right)$, and TOTP $(\mathrm{F}=$ $\left.09.83_{3,3}, \mathrm{p}=0.0463\right)$.

For peat, in the structure $x$ peat (EXT Table 8) ANOVAs: without and with the interaction term request, there was significance for indispensable HIS, dispensable GLU, and TOTP; without the interaction term request there was significance for CRDP; and with the interaction term request there was significance for indispensable MET and CYS. These results (EXT Table 8) supported $\mathrm{H}_{1}$ for the peat hypothesis. For peat in the structure x peat ANOVAs (EXT Table 8): without and with the interaction term request there was no significance for indispensable ARG, ISO, LEU, LYS, PHE, THR, TRP and VAL; without the interaction term request there was no significance for indispensable MET and dispensable CYS; and with the interaction term request there was no significance for CRDP. These
ANOVA results (EXT Table 8) were in support of $\mathrm{H}_{0}$ for the peat hypothesis. Thus, results from the structure x peat ANOVA (EXT Table 8) were split in their support and negation of the peat hypothesis.

\section{Positive Results in the Structure $x$ Peat LS-Means with no Greenhouse Data for var. ' $T$ '}

In the structure $\mathrm{x}$ peat LS-Means analyses (EXT Table 18): most indispensable and dispensable amino acids and CRDP were highly significant for all levels of peat for leaf while significant for all levels of peat for root; only indispensable MET was highly significant for all levels of peat for both leaf and root; and TOTP was highly significant for all levels of peat for leaf and for the control for root while significant for other levels of peat. These results supported $\mathrm{H}_{1}$ in both the structure and peat hypotheses and are described in more detail in SI.

Table 4. Crude protein, combined positive results from Tukey adjusted LS-Means for M. expansa.

\begin{tabular}{|c|c|c|c|}
\hline CRDP & Structure & Var. ' $L$ ' LS Means & Var. 'T' LS Means \\
\hline EXT TABLE & 11: Structure $\mathrm{x}$ variety with & $\begin{array}{l}\text { greenhouse leaf and } \\
\text { var. ' } L \text { ', }\end{array}$ & $\begin{array}{l}\text { for var. ' } T \text { ': } \\
\text { var. ' } T\end{array}$ \\
\hline CRDP & leaf & $29.37 \pm 0.76_{\mathrm{A}} * *$ & $22.52 \pm 1.52_{\mathrm{B}} * *$ \\
\hline CRDP & root & $8.89 \pm 0.76_{\mathrm{C}} * *$ & $11.42 \pm 1.08_{\mathrm{C}}^{* *}$ \\
\hline CRDP & stem & & $8.78 \pm 1.52_{\mathrm{C}} *$ \\
\hline \multicolumn{2}{|l|}{ EXT TABLE } & $\begin{array}{l}\text { greenhouse leaf data } \\
\text { var. ' } L \text { ' }\end{array}$ & $\begin{array}{l}\text { ing stem for var. ' } T \text { ': } \\
\text { var. ' } T\end{array}$ \\
\hline CRDP & leaf & $29.37 \pm 0.76_{\mathrm{A}} * *$ & $22.52 \pm 1.52_{\mathrm{B}} * *$ \\
\hline CRDP & root & $8.89 \pm 0.76_{\mathrm{C}} * *$ & $11.42 \pm 1.08_{\mathrm{C}} * *$ \\
\hline EXT TABLE & 13: Structure $\mathrm{x}$ variety with & $\begin{array}{l}\text { no greenhouse data } \\
\text { var. ' } L \text { ' }\end{array}$ & var. ' $T$ \\
\hline CRDP & leaf & $29.37 \pm 0.76_{\mathrm{A}} * *$ & \\
\hline CRDP & root & $8.89 \pm 0.76_{\mathrm{B}} * *$ & $11.42 \pm 1.08_{\mathrm{B}} * *$ \\
\hline \multicolumn{4}{|c|}{ EXT TABLE 14: Variety x COA - no positive results for crude protein } \\
\hline \multicolumn{4}{|c|}{ EXT TABLE 15: Variety x peat: } \\
\hline & & var. ' $L$ ' & var. ' $T$ ' \\
\hline CRDP & control & $19.09 \pm 6.49_{\mathrm{A}} *$ & $8.94 \pm 12.99_{\mathrm{A}}$ \\
\hline CRDP & $\mathrm{P}$ & $19.37 \pm 9.18_{\mathrm{A}}$ & \\
\hline CRDP & PP & & $13.91 \pm 12.99_{\mathrm{A}}$ \\
\hline CRDP & PPP & $18.97 \pm 9.18_{\mathrm{A}}$ & \\
\hline \multicolumn{4}{|c|}{ EXT TABLE 16: Variety x steer manure: } \\
\hline & & var. ' $L$ ' & var. ' $T$ ' \\
\hline CRDP & control & $18.63 \pm 6.48_{\mathrm{A}} *$ & $13.91 \pm 12.97_{\mathrm{A}}$ \\
\hline CRDP & SSS & $19.37 \pm 9.17_{\mathrm{A}}$ & \\
\hline CRDP & SSSS & & $8.94 \pm 12.97 \mathrm{~A}$ \\
\hline CRDP & SSSSS & $19.88 \pm 9.17_{\mathrm{A}}$ & \\
\hline \multicolumn{4}{|c|}{ EXT TABLE 17: Structure x COA - no positive results } \\
\hline \multicolumn{4}{|c|}{ EXT TABLE 18: Structure x peat: } \\
\hline & & leaf & root \\
\hline CRDP & control & $29.68 \pm 0.68_{\mathrm{A}} * *$ & $8.64 \pm 0.56_{\mathrm{B}} *$ \\
\hline CRDP & $\mathrm{P}$ & $29.43 \pm 0.96_{\mathrm{A}} * *$ & $9.31 \pm 0.96_{\mathrm{B}} *$ \\
\hline CRDP & PP & & $13.91 \pm 0.96_{\mathrm{B}} *$ \\
\hline CRDP & PPP & $28.70 \pm 0.96_{\mathrm{A}} * *$ & $9.25 \pm 0.96_{\mathrm{B}} *$ \\
\hline \multicolumn{4}{|c|}{ EXT TABLE 19: Structure x steer manure: } \\
\hline & & leaf & root \\
\hline CRDP & control & $28.70 \pm 1.82_{\mathrm{A}} *$ & $10.35 \pm 1.49_{\mathrm{A}}^{*}$ \\
\hline CRDP & SSS & $29.43 \pm 2.58_{\mathrm{A}} *$ & $9.31 \pm 2.58_{\mathrm{A}}^{*}$ \\
\hline CRDP & SSSS & & $8.94 \pm 2.58_{\mathrm{A}} *$ \\
\hline CRDP & SSSSS & $30.66 \pm 2.58_{\mathrm{A}} *$ & $9.11 \pm 2.58_{\mathrm{A}} *$ \\
\hline \multicolumn{4}{|c|}{ EXT TABLE 20: Peat $\mathrm{x}$ steer manure - no positive results for crude protein } \\
\hline \multicolumn{4}{|c|}{$\begin{array}{l}\text { Notes: Tukey adjusted LS Means include SDs among levels of independent variables for CRDP, letters showing } \\
\text { similar T ukey adjusted LS Means, and asterisks indicat ing degrees of significance; leaf and root were levels of } \\
\text { structure for both varieties; percentages were levels of peat and steer manure, respectively. } \\
\text { Abbre viation sor in de pen dent variables and their le vels: COA }=\text { combined organic amendments }=\text { peat plots and } \\
\text { steer manure plots and plots cont aining both; control = all sand; steerM }=\text { steer manure; } \mathrm{P}=1 \% \text { peat (same as PSSS } \\
\text { plots) PP }=2 \% \text { peat; PPP }=3 \% \text { peat; PSSS }=1 \% \text { peat with } 3 \% \text { steerM in the same plot; SSS }=3 \% \text { steerM (same as } \\
\text { PSSS plots); SSSS }=4 \% \text { steerM; SSSSS }=5 \% \text { steerM. } \\
\text { Ami no acid abbreviation: CRDP }=\text { crude protein. } \\
\text { Other Abbreviations: EXT }=\text { Extended T able(s) from Appendix C-7 of Kritzer Van Zant's (2016a) dissertation. }\end{array}$} \\
\hline
\end{tabular}


Table 5. Total protein, combined results from ANOVAs for M. expansa.

\begin{tabular}{llllll}
\hline I or none & IndpV & DepV & F Value & $\mathbf{d f}_{1}, \mathbf{d f}_{2}$ & $\begin{array}{l}\mathrm{p} \text {-value } \\
=\text { Pr }>\text { F for } \\
\end{array}$ \\
& & $\begin{array}{l}\text { p-value } \\
\text { significance } \\
\text { at .05 level }\end{array}$ \\
\hline
\end{tabular}

EXT TABLE 1: Structure $\mathrm{x}$ variety with greenhouse leaf and stem data for var. ' $T$ ':

\begin{tabular}{|c|c|c|c|c|c|c|}
\hline & strc & ТОТР & 76.21 & 2,8 & $<.0001$ & $* *$ \\
\hline I & strc & TOTP & 407.95 & 2,7 & $<.0001$ & $* *$ \\
\hline I & $\mathrm{v}$ & ТОТР & 34.99 & 1,7 & 0.0006 & * \\
\hline I & $\mathrm{strc}^{*} \mathrm{v}$ & TOTP & 68.60 & 1,7 & $<.0001$ & $* *$ \\
\hline \multicolumn{7}{|c|}{ EXT TABLE 2: Structure $\mathrm{x}$ variety with greenhouse leaf data not including stem for var. ' $T$ ': } \\
\hline & strc & TOTP & 149.56 & 1,8 & $<.0001$ & $* *$ \\
\hline I & strc & TOTP & 807.52 & 1,7 & $<.0001$ & W \\
\hline I & $\mathrm{v}$ & ТОТР & 34.99 & 1,7 & 0.0006 & * \\
\hline I & $\mathrm{strc}^{*} \mathrm{v}$ & TOTP & 68.60 & 1,7 & $<.0001$ & $* *$ \\
\hline \multicolumn{7}{|c|}{ EXT TABLE 3: Structure $\mathrm{x}$ variety with no greenhouse data for var. ' $T$ ': } \\
\hline & strc & ТОТР & 1346.86 & 1,7 & $<.0001$ & \\
\hline & strc & ТОTP & 1346.86 & 1,7 & $<.0001$ & \\
\hline
\end{tabular}

EXT TABLE 4: Variety x COA - no positive results

EXT TABLE 5: Variety $x$ peat - no positive results

EXT TABLE 6: Variety $x$ steer manure - only dispensable HLY had positive results EXT TABLE 7: Structure x COA:

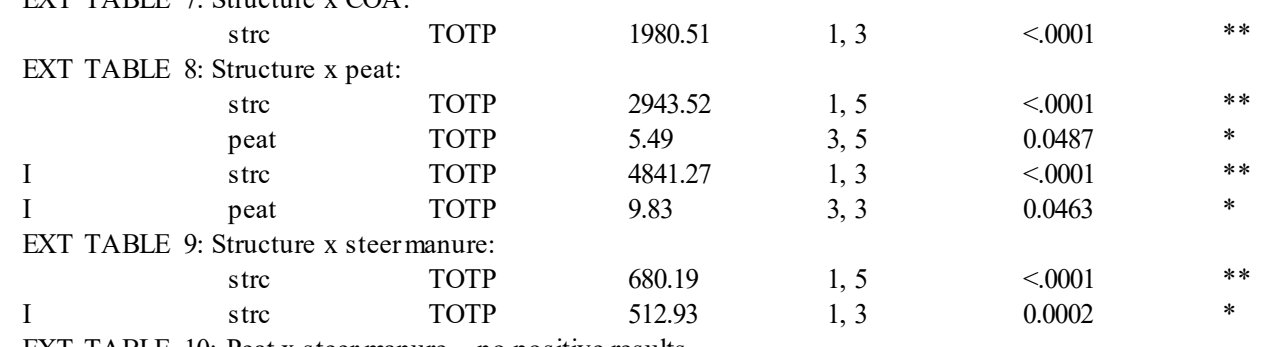

EXT TABLE 10: Peat $\mathrm{x}$ steer manure - no positive results

\begin{abstract}
Abbre viations for independent variables and their levels: $\mathrm{COA}=$ combined organic amendments $=$ peat plots and steer manure plots and plots containing both; strc $=$ structure; $\mathrm{v}=$ variety; strc $^{*} \mathrm{v}=$ interaction

Amino acid abbreviation: $\mathrm{TOTP}=$ total protein

O ther Abbreviations: DepV = Dependent variable; $\mathrm{df}_{2}=$ error; $\mathrm{EXT}=$ Extended T able(s) from Appendix C-7 of Kritzer Van Zant's (2016a)

dissertation; I=Interaction requested vs none $=$ blank space $=$ no interaction requested; $I n d p V=$ Independent variable

Key to symbols: One asterisk $(*)$ indicates significance at the .05 to 0.001 level of probability; Two asterisks $\left({ }^{* *}\right)$ indicates high significance at the .0001 or less level of probability.
\end{abstract}

\section{Positive Results for structure in the structure $x$ steer ma- nure ANOVAs with no greenhouse data for var. ' $T$ '}

Positive results for structure for the indispensable amino acids and totals in the ANOVAs for the independent variables of structure $\mathrm{x}$ steer manure with no greenhouse data for var. ' $T$ ' (EXT Table 9), without the interaction term request, were all highly significant for: ARG $\left(\mathrm{F}=2025.80_{15}, \mathrm{p}=<.0001\right)$; HIS ( $\mathrm{F}$ $\left.=349.07_{1,5}, \mathrm{p}=<.0001\right)$; ISO $\left(\mathrm{F}=1142.19_{15}, \mathrm{p}=<.0001\right)$; LEU $\left(\mathrm{F}=1351.60_{1.5}, \mathrm{p}=<.0001\right) ; \mathrm{LYS}\left(\mathrm{F}=758.89_{1,5}, \mathrm{p}=<.0001\right) ;$ MET $\left(\mathrm{F}=691.67_{1,5}, \mathrm{p}=<.0001\right)$; PHE $\left(\mathrm{F}=1960.96_{15}, \mathrm{p}=\right.$ $<.0001)$; THR $\left(\mathrm{F}=1176.57_{15}, \mathrm{p}=<.0001\right)$; TRP $\left(\mathrm{F}=517.86_{1,5}\right.$, $\mathrm{p}=<.0001)$; VAL $\left(\mathrm{F}=1138.65_{15}, \mathrm{p}=<.0001\right) ; \mathrm{CRDP}(\mathrm{F}=$ $\left.175.15_{1,5}, \mathrm{p}=<.0001\right)$; and TOTP $\left(\mathrm{F}=680.19_{1,5}, \mathrm{p}=<.0001\right)$.

Positive results for structure in the structure $\mathrm{x}$ steer manure ANOVAs (EXT Table 9) with the interaction term request are: highly significant for indispensable amino acids and totals ARG (2384.87 $1,3, \mathrm{p}=<.0001)$, ISO $\left(\mathrm{F}=1272.03_{1,3}, \mathrm{p}=<.0001\right)$, LEU $\left(\mathrm{F}=1383.86_{1.3}, \mathrm{p}=<.0001\right), \operatorname{MET}\left(\mathrm{F}=632.51_{1,3}, \mathrm{p}=0.0001\right)$, PHE $\left(\mathrm{F}=2014.62_{1,3}, \mathrm{p}=<.0001\right)$, THR $\left(\mathrm{F}=1348.53_{1,3}, \mathrm{p}=\right.$ $<.0001)$, VAL $\left(\mathrm{F}=1216.60_{1,3}, \mathrm{p}=<.0001\right)$, and $\mathrm{CRDP}(\mathrm{F}=$ $\left.111.92_{1,3}, p=0.0018\right)$; and significant for HIS $\left(F=253.92_{1,3}, p=\right.$
0.0005), LYS $\left(\mathrm{F}=540.08_{1,3}, \mathrm{p}=0.0002\right), \mathrm{TRP}\left(\mathrm{F}=515.86_{1,3}, \mathrm{p}\right.$ $=0.0002)$, and TOTP $\left(\mathrm{F}=512.93_{1,3}, \mathrm{p}=0.0002\right)$.

For structure in the ANOVAs for structure $\mathrm{x}$ steer manure (EXT Table 9) without and with the interaction term request, all ten indispensable amino acids and both CRDP and TOTP, were again significant or highly significant in full agreement with $\mathrm{H}_{1}$ in the structure hypothesis. This was in full agreement for structure with the results from structure x peat (EXT Table 8). In addition, for structure in the ANOVAs for structure $\mathrm{x}$ steer manure (EXT Table 9), without the interaction term request indispensable HIS, LYS and TRP were also highly significant in full agreement with $\mathrm{H}_{1}$ in the structure hypothesis, and with the interaction term request were significant in agreement with $\mathrm{H}_{1}$ in the structure hypothesis.

\section{Results for steer manure in the structure $x$ steer manure ANOVAs with no greenhouse data for var. ' $T$ '}

Results for steer manure in the structure $\mathrm{x}$ steer manure ANOVAs (EXT Table 9) had no significance, consistently supporting $\mathrm{H}_{0}$ for the steer manure hypotheses. 
Table 6. Total protein, combined results from Tukey adjusted LS-Means for M. expansa.

\begin{tabular}{|c|c|c|c|}
\hline TOTP & Structure & Var. ' $L$ ' LS Means & Var. ' $T$ ' LS Means \\
\hline \multicolumn{4}{|c|}{ EXT TABLE 11: Structure $x$ variety with greenhouse leaf and stem data for var. ' $T$ ': } \\
\hline TOTP & leaf & $23.80 \pm 0.35_{\mathrm{A}} * *$ & $16.80 \pm 0.70_{\mathrm{B}} * *$ \\
\hline TOTP & root & $5.70 \pm 0.35_{C}^{* *}$ & $6.87 \pm 0.49_{\mathrm{C}} * *$ \\
\hline TOTP & stem & & $5.99 \pm 0.70_{\mathrm{C}} * *$ \\
\hline \multicolumn{4}{|c|}{ EXT TABLE 12: Structure $x$ variety with greenhouse leaf data not including stem for var. ' $T$ ': } \\
\hline TOTP & leaf & $23.80 \pm 0.35_{\mathrm{A}} * *$ & $16.80 \pm 0.70_{\mathrm{B}} * *$ \\
\hline TOTP & root & $5.70 \pm 0.35_{C} * *$ & $6.87 \pm 0.49_{\mathrm{C}} * *$ \\
\hline \multicolumn{4}{|c|}{ EXT TABLE 13: Structure $\mathrm{x}$ variety with no greenhouse data for var. ' $T$ ': } \\
\hline TOTP & leaf & $23.80 \pm 0.35_{\mathrm{A}} * *$ & \\
\hline TOTP & root & $5.70 \pm 0.35_{\mathrm{B}} * *$ & $6.87 \pm 0.49_{\mathrm{B}} * *$ \\
\hline \multicolumn{4}{|c|}{ EXT TABLE 14: Variety x COA -no positive results for total protein } \\
\hline \multicolumn{4}{|c|}{ EXT TABLE 15: Variety x peat - no positive results for total protein } \\
\hline \multicolumn{4}{|c|}{ EXT TABLE 16: Variety x steer manure - no positive results for total protein } \\
\hline \multicolumn{4}{|c|}{ EXT TABLE 17: Structure x COA - no positive results } \\
\hline \multicolumn{4}{|c|}{ EXT TABLE 18: Structure x peat: } \\
\hline TOTP & control & $23.97 \pm 0.25_{\mathrm{A}} * *$ & $5.62 \pm 0.20_{\mathrm{B}} * *$ \\
\hline TOTP & $P$ & $24.43 \pm 0.35_{\mathrm{A}} * *$ & $5.98 \pm 0.35_{\mathrm{B}} *$ \\
\hline TOTP & PP & & $7.76 \pm 0.35_{\mathrm{B}} *$ \\
\hline TOTP & PPP & $22.84 \pm 0.35_{\mathrm{A}} * *$ & $5.94 \pm 0.35_{\mathrm{B}} *$ \\
\hline \multicolumn{4}{|c|}{ EXT TABLE 19: Structure x steer manure: } \\
\hline TOTP & control & $23.26 \pm 0.77_{\mathrm{A}} * *$ & $6.35 \pm 0.63_{\mathrm{B}} *$ \\
\hline TOTP & SSS & $24.43 \pm 1.09_{\mathrm{A}} *$ & $5.98 \pm 1.09_{\mathrm{B}} *$ \\
\hline TOTP & SSSS & & $5.98 \pm 1.09_{\mathrm{B}} *$ \\
\hline TOTP & SSSSS & $24.25 \pm 1.09_{\mathrm{A}} *$ & $5.55 \pm 1.09_{\mathrm{B}} *$ \\
\hline
\end{tabular}

Notes: Tukey adjusted LS Means include SDs among levels of independent variables for TOTP, letters showing similar Tukey adjusted LS Means, and asterisks indicating degrees of significance; leaf and root were levels of structure for both varieties; percentages were levels of peat and st eer manure, respectively.

Abbre viations for in de pen dent variables and their le vels: $\mathrm{COA}=$ combined organic amendments $=$ peat plots and steer manure plots and plots containing both; control = all sand; steerM = steer manure; $\mathrm{P}=1 \%$ peat (same as PSSS plots) $\mathrm{PP}=2 \%$ peat $; \mathrm{PPP}=3 \%$ peat PSSS $=1 \%$ peat with $3 \%$ steerM in the same plot; SSS $=3 \%$ steerM (same as PSSS plots); SSSS $=4 \%$ steerM; SSSS $=5 \%$ steerM.

Abbre viation for amino acid: TOTP $=$ total protein

O ther Abbreviations: EXT = Extended T able(s) from Appendix C-7 of Kritzer Van Zant's (20 16a) dissertation.

Key to symbols: One asterisk $\left(^{*}\right)$ indicates significance at the .05 to 0.001 level of probability; Two asterisks $\left({ }^{* *}\right)$ indicates high significance at the .0001 or less level of probability.

\section{Positive Results in the structure $x$ steer manure LS-Means with no greenhouse data for var. ' $T$ '}

In the structure $\mathrm{x}$ steer manure LS-Means analyses (EXT Table 19; see results in SI 3.4 and Tables 2, 4 and 6): most indispensable and dispensable amino acids were highly significant for leaf while significant for structure for all levels of steer manure; indispensable MET and TRP were only highly significant for leaf for the control for steer manure, while significant for all other level combinations for leaf and all level combinations for root; TOTP was highly significant for the control for leaf, significant for all other levels of steer manure for leaf, and for all levels of steer manure for root; and CRDP was significant for all levels of steer manure for leaf and root. These results (EXT Table 19; see results in SI 3.4 and Tables 2, 4 and 6) supported $\mathrm{H}_{1}$ for both the structure and steer manure hypothesis, and were in contradiction to the ANOVAs (EXT Table 9) for the same pair-wise comparison of independent variables. Specifics for these results are given in SI.

\section{Results for peat and steer manure, in the peat $x$ steer ma- nure ANOVAs with no greenhouse data for var. ' $T$ '}

There were no positive results in the ANOVAs for the independent variables peat $\mathrm{x}$ steer manure (EXT Table 10). Detailed results were given from the peat $\mathrm{x}$ steer manure Tukeyadjusted LS-Means (SI).

For peat in the peat $\mathrm{x}$ steer manure (EXT Table 10) analyses, without and with the interaction term request, there was no significance for any amino acid, CRDP or TOTP, which was in full support of $\mathrm{H}_{0}$ for the peat hypothesis. However, in the structure $x$ peat (EXT Table 18) LS-Means analyses, most amino acids and CRDP (See SI 3.3, and Tables 2, 4 and 6) supported $\mathrm{H}_{1}$ in the peat hypothesis. This may have indicated that there was an effect of peat on amino acid production. Peat in the peat $\mathrm{x}$ steer manure (EXT Table 20) LS-Means analyses, was not significant for any level combination for all ten indispensable amino acids, most dispensable amino acids, and was not significant for either CRDP or TOTP. Therefore, in the peat $\mathrm{x}$ steer manure 
LS-Means analyses most dependent variables supported $\mathrm{H}_{0}$ in both the peat and steer manure hypotheses.

Indispensable amino acids for the most part, and CRDP and TOTP, were present in higher amounts in leaf over root. Results for structure were most frequently in support of $\mathrm{H}_{1}$ for the structure hypothesis. This was seen with and without the interaction term request in the structure $\mathrm{x}$ peat (EXT Table 8 ) and structure $x$ steer manure (EXT Table 9) ANOVAs. Considerable significance for level combinations and thus for $\mathrm{H}_{1}$ in the peat hypothesis was also seen in the structure x peat LS-Means analyses (EXT Table 18; see SI 3.3 and Tables 2, 4 and 6). Additionally, there was some significance amongst level combinations in the structure x steer manure LS-Means analyses (EXT Table 19; see results in SI 3.4 and Tables 2, 4 and 6), which further gave support to $\mathrm{H}_{1}$ in the structure hypothesis.

Results for steer manure consistently supported $\mathrm{H}_{0}$ for the steer manure hypotheses from the structure $\mathrm{x}$ steer manure ANOVAs (EXT Table 9). However, results from the structure $x$ steer manure LS-Means analyses (EXT Table 19) supported $\mathrm{H}_{1}$ in the steer manure hypothesis. This contradicted the ANOVAs (EXT Table 9) for steer manure for the same pair-wise comparison of independent variables. Detailed results for steer manure from other analyses are in SI.

It can be said that in the ANOVAs, most of the results concerned with peat vs. steer manure, showed a mild influence from peat on the amino acid profiles for M. expansa. It will require larger experiments and proper mathematical consideration to learn if the effect of steer manure is truly non-existent. Yet, especially from the LS-Means results, it appears that either soil amendment may have given a slight benefit to production of at least some amino acids. This discrepancy may have been because soil amendments increased water retention in the root zone, which $M$. expansa reacts poorly to, vs. amendments as nutrient sources. As amendments had been added to plots years before the work on $M$. expansa commenced, effects may have been magnified successfully by the uniform additions of a small amount of mushroom composted horse manure, under each plant at planting time. There was contradiction in results for peat and steer manure from other analyses (SI). However, those analyses included variety as an independent variable, so were not used to resolve the hypotheses. There were also additional considerations covered in the SI.

Southern Illinois research on $M$. expansa was unfunded, and native southern Illinois soils retain water too readily for the crop to survive. These issues limited the scale of production and slowed the speed of many steps along the way. However, this research has increased understanding of the growth and nutritional value of this ancient, endangered crop. Funding is recommended for research on $M$. expansa to: find more horticultural and wild varieties, save and protect all known remaining horticultural and wild varieties; complete taxonomic work on wild Andean species by Kritzer Van Zant and publication of that work; expand taxonomic work on the existing horticultural varieties to the basic taxonomic work on wild species; begin molecular research in several areas relevant to wild $M$. expansa, the crop, and its potential uses; identify and test more locations with seemingly suitable conditions to grow the crop; examine the potential of M. expansa and other Mirabilis spp. for floriculture and landscaping in arid regions, and for roof top gardens as these plants are tolerant of high UV conditions and high and low temperature extremes, support multiple species of native pollinators, and require little water; investigate $M$. expansa and other Mirabilis spp. for their potential to stabilize loose soils on cliffs and hillsides, with their unusual ability to send rhizomes deeply into or toward water tables while remaining anchored by their roots within dry root zones in loose soils; test the effectiveness of fermentation and methods of separation of protein and starch in $M$. expansa for dealing with anti-nutrients; test mature $M$. expansa varieties grown under different conditions and for longer periods of time than material previously tested, for the presence of useful micro-molecules including volatile micro-molecules; test for medicinal and further agricultural benefits from the known enzyme inhibitors in $M$. expansa and other Mirabilis spp., and their component peptides, some already shown to have species specific effects on agriculturally significant bacteria and fungi; examine the epigenetic variation in Mirabilis, including M. expansa wild and crop varieties; support indigenous and Andean agency efforts to continue growing traditional varieties of the crop where they still remain; begin modern breeding programs for the crop in locales with sufficient drainage and other appropriate conditions around the world; and further investigate the value of M. expansa for forage and feed. More than one of these recommendations may be relevant to finding solutions to address the effects of climate change on food production. $M$. expansa can serve as an important test case for why old crops matter, even when to date, there is no variety of the same taxa commonly in production.

\section{Supporting Information Description}

SI includes information from EXT Tables 1-20. EXT Tables 1-10 contained positive results from ANOVA analyses. EXT Tables 11-20 contained positive results from Tukey adjusted LS-Means analyses. EXT Table 1 correlates with EXT Table 11, EXT Table 10 with EXT Table 20, etc., so that tables of the same pair-wise comparisons of independent variables were numbered ending in the same digit (Kritzer Van Zant 2016a). Extended Table numbers were also used in short descriptions of pair-wise comparisons that did not produce positive results. This kept ending digits consistent for sets of pair-wise comparisons and matched earlier number designations for extended tables with negative and non-computed data in Appendix C-7 (Kritzer Van Zant 2016a) and for graphs depicting the ANOVA results in Appendix C-8 (Kritzer Van Zant 2016a). SI for this paper also includes discussion of interaction terms from some of the ANOVAs, and all analyses with COA or variety as independent variables, as there were no hypotheses for those variables. Conflicting results for both occurred frequently, as COA and variety had more caveats for the raw data. Additional information is given in SI, for Materials and Methods summarized from previous papers for the reader's convenience. Additional considerations are also given for statistics. All text description of specifics for positive results from the Tukey adjusted LS-Means analyses not in the summary tables in the main paper, are also 
in the SI due to their length. EXT Tables 1-3 and 11-13 were for different data configurations of structure $\mathrm{x}$ variety. Those differences were also addressed in the SI along with reasons for only considering the versions of the exploratory structure $\mathrm{x}$ variety tables with the most complete data, in the main text above.

\section{Acknowledgements}

Thank you to Jim Persinger, Bill Barthalomew, John Haddock, Ken Diesburg, John Miller, and the Horticultural Research Center, all at SIU-C. Advice and assistance on statistics for this chapter, were given by John D. Reeve of Southern Illinois University. Thank you in memoriam to Abraham Kritzer.

\section{Author Contributions}

Ground preparation, planting and weeding of plots, lyophilization, statistical analyses, preparation and sending of samples for profiling, and writing, were done by Miriam Kritzer Van Zant. David A. Lightfoot assisted with lab space for extractions, access to sand plots and the greenhouse, advice and encouragement. William J. Banz made arrangements for the profiling and helped with editing. Gary Apgar also assisted with the statistical analyses.

\section{References}

Gendall, H, J Seminario, M Sørensen, and I Theilade (2019) Unearthing the "lost" Andean root crop "mauka" (Mirabilis expansa [Ruíz \& Pav.] Stand1.). Econ. Bot. XX(X): 1-18. Downloaded 20 Aug 2019 from: https://link.springer.com/article/10.1007/s12231-01909467-y.

Horwitz, W, GW Latimer $(2006,2011)$ Chapter 45.3.05 Official method 982.30 E (a, b, c). In W Horowitz, GW Latimer (eds.) Official Methods of Analysis of AOAC International $18^{\text {th }}$ edition, revision 1. AOAC International: Gaithersburg, MD.

House, JD, J Neufeld, and G Leson (2010) Evaluating the quality of protein from hemp seed (Cannabis sativa L.) products through the use of the protein digestibility-corrected amino acid score method. J Agric Food Chem 58: 11801-11807. downloaded 11 Apr 2017 from: http://pubs.acs.org/doi/abs/10.1021/jf102636b.

Kritzer Van Zant, M (2016a) Analysis and Development of Mirabilis expansa (Ruiz and Pav.) Standl.; For Potential as a New Root Crop Outside the Andes (doctoral dissertation). ProQuest Dissertations and Theses Accession Order No. 12694, pp. i-xxvii, 1-352, and 9 Appendices on CD.

Kritzer Van Zant, M (2016b) Review of the Economic and Ethnobotany of the Family Nyctaginaceae. Atlas J of Bio doi: 10.5147/ ajb.2016.0139, 249-266. downloaded 8 Jun 2017 from: http:// www.atlas-publishing.org/wp-content/uploads/2013/07/35-AJBVan_Zantl_2016b-139.pdf.

Kritzer Van Zant, M (2017) History of Mirabilis expansa (Ruiz and Pav.) Standl.; Growth and use in the Andes. Atlas J of Bio doi: 10.5147/ajb.2016.0138, 236-248. downloaded 8 Jun 2017 from: http:/www.atlas-publishing.org/wp-content/uploads/2013/07/34-
AJB-Van Zantl 2016-0138.pdf.

Kritzer Van Zant, M, K Diesburg, and DA Lightfoot (2018) Mirabilis expansa Growth, Yield, and Quality Traits: First US Field Trials for an Ancient, Endangered, Andean Crop. Atlas J of Bio doi: https:// doi.org/10.5147/ajb.v0i0.174, 551-574.

Kritzer Van Zant, M, WJ Banz, HB Chai, G Apgar, DA Lightfoot (2019) Amino acid profiles and cytotoxicity of Mirabilis expansa (Ruiz and Pav.) Standl.; Baseline data for a rare indigenous Andean crop. Adv Nutri and Food Sci: ANAFS-126: 1-18. downloaded 18 Apr 2019 from: https://www.kosmospublishers.com/wp-content/ uploads/2019/04/Amino-Acid-Profiles-and-Cytotoxicity-of-Mirabilis-expansa-Ruiz-and-Pav.-Standl.-Baseline-Data-for-A-RareIndigenous-Andean-Crop.pdf.

Li, X, YB Kim, M Romij Uddin, S Lee, S-J Kim, and SU Park (2013) Influence of light on the free amino acid content and $\gamma$-aminobutyric acid synthesis in Brassica juncea seedlings. J Agric Food Chem 61: 8624-8631. Downloaded 9 Feb 2017 from: https://www.researchgate.net/publication/255174673_Influence_of_Light_on Free_Amino_Acids_Content_and_g-Aminobutyric_Acid_Synthesis_in_Brassica_juncea_Seedlings.

Maulina, D, SB Sumitro, M Amin, SR Lestari (2018) Identification of peptides compounds from Mirabilis jalapa L. (Caryophyllales: Nyctaginaceae) Potentially as a Biopesticide IOP Conf. Series: Journal of Physics: Conf. Series 1093 (2018) 012009 doi :10.1088/1742-6596/1093/1/012009.

Reeds, PJ (2000) Criteria and significance of dietary protein sources in humans. J Nutr 130: 1835S-1840S. downloaded 9 Feb 2017 from: http://jn.nutrition.org/content/130/7/1835S.full?related-urls=yes\&1 egid=nutrition;130/7/1835S.

Schmidt, JA, S Rinaldi, A Scalbert, P Ferrari, D Achaintre, MJ Gunter, PN Appleby, TJ Key, and RC Travis (2016) Plasma concentrations and intakes of amino acids in male meat-eaters, fish-eaters, vegetarians and vegans: a cross-sectional analysis in the EPIC-Oxford cohort. Eur J Clin Nutr 70(3): 306-312. doi:10.1038/ejcn.2015.144 downloaded 9 Feb 2017 from: http://www.nature.com/ejcn/journal/ v70/n3/full/ejen2015144a.html.

Seminario, J, D Chalampuente-Flores, H Gendall, M. Sørensen (2019) The agronomy of Mauka (Mirabilis expansa (Ruíz \& Pav.) Standl.) - A review. J of Plant Gen and Crop Research 1(2) downloaded 1 Jul 2019 from: https://openaccesspub.org/jgrc/article/997.

Thanapornpoonpong S-n, S Vearasilp, E Pawelzik, and S Gorinstein (2008) Influence of various nitrogen applications on protein and amino acid profiles of amaranth and quinoa. J Agric Food Chem 56: 1164-11470. downloaded 9 Feb 2017 from: http://pubs.acs.org/ doi/abs/10.1021/jf802673x.

WHO (2007) Protein and Amino Acid Requirements in Human Nutrition; WHO Technical Report Series 935. WHO, Singapore, Pp. xi, 265. downloaded 9 Feb 2017 from: http://apps.who.int/iris/bitstream/10665/43411/1/WHO_TRS_935_eng.pdf?ua=1.

Woolf, PJ, LL Fu, A Basu (2011) vProtein: Identifying optimal amino acid complements from plant-based foods. PLoS ONE 6(4): e18836 Doi: doi.org/10.1371/journal.pone.0018836. Downloaded 9 Feb 2017 from: http://journals.plos.org/plosone/article?id=10.1371/ journal.pone.0018836.

Zarkadas, CG (1997) Assessment of the protein quality of native white floury maize, designated IAPO-13, by amino acid analysis. J Agric Food Chem 45: 1062-1069. downloaded 11 Apr 2017 from: http:// pubs.acs.org/doi/pdf/10.1021/jf960573o. 


\section{Van Zant et al. (2019) Supporting Information}

\section{Supporting Information (SI)}

\section{SI Materials and Methods}

Despite imperfect matches for plot types, some differences in results for percentages of amino acids between the two Andean horticultural varieties of $M$. expansa were clear. This clarity was particularly noticeable in the structure $\mathrm{x}$ variety LSMeans exploratory analyses (EXT (Extended) Tables 11, 12 and 13). Table numbers that were used previously (Kritzer Van Zant 2016a), are described as EXT tables with the same table numbers, in the main text above and SI, for the same pairs of variables.

Var. ' $T$ ' material was not grown in the exact same kinds of plots and for only one of the same years as var. ' $L$ ' (Kritzer Van Zant et al., 2018), therefore there was no hypothesis for the independent variable variety, though data for both varieties were subjected to ANOVAs and Tukey-adjusted LS-Means analyses to explore differences in amino acid percentages between them. Varieties ' $L$ ' and ' $T$ ' were the levels of the independent variable variety. Only analyses including variety as an independent variable incorporate data for var. ' $T$ ' grown in 2009 (Kritzer Van Zant et al. 2018). This was the single good year of its production in Illinois (Kritzer Van Zant et al., 2018). Var. ' $L$ ' data was the product of growth in 2008 and 2009 (Kritzer Van Zant et al., 2018). Though variety was analyzed as an independent variable, the ANOVAs and LS-Means analyses for variety were not statistically meaningful for any of the hypotheses presented, and were only an exploration of differences between the two varieties. Var. ' $T$ ' was grown outdoors in plots with slightly different percentages of peat and steer manure than plots used to grow var. ' $L$ '. Despite this dissimilarity, percentages of peat and steer manure were each consecutively dispersed. This made comparison of levels for each variety easier. Discrepancies within the amino acid profile data also included imperfect matching from each variety having been grown in different years. In addition, some var. ' $T$ ' material came from greenhouse-grown plants that were never in the field. Independent variable variety was examined in the structure $\mathrm{x}$ variety (EXT Tables 1-3, 11-13), variety x COA (EXT Tables 4, 14), variety x peat (EXT Tables 5, 15) and variety $\mathrm{x}$ steer manure (EXT Tables 6,16 ) ANOVAs (EXT Tables 1-6) and LS-Means analyses (EXT Tables 11-16). Results from these tables are given in the text in full below, and included data for dispensable amino acids included in the assays.

COA analyses included all individual plots planted in the 2009 repeat experiment with var. ' $L$ ', containing different percentages of peat and steer manure separately, as well as the plots containing a mixture of both. Effects from the plots containing both soil amendments could have been due to peat, steer manure or synergistically from both.

Peat vs. steer manure was considered in a separate set of ANOVAs (EXT Table 10) and LS-Means (EXT Table 20) analyses, which combined data for both varieties. Again, these analyses were not statistically meaningful, and were only explored for obvious patterns.

\section{SI Statistics}

One set of ANOVA analyses (EXT Table 1) and one set of LS-Means analyses for structure x variety (EXT Table 11), were run including both exclusively greenhouse-grown var. ' $T$ ' above ground samples. Structure $\mathrm{x}$ variety was reanalyzed in ANOVAs and LS-Means twice more, first with the lone var. ' $T$ ' stem sample from the green house excluded from the analyses (EXT Tables 2, 12), and then excluding both greenhouse-grown data points for var. ' $T$ ' (EXT Tables 3, 13). Only the most inclusive of the three structure $\mathrm{x}$ variety ANOVAs (EXT Table 1) and LS-Means analyses (EXT Table 11) were used for text description and comparison to other pairs of independent variables, for both structure and variety. Results of all analyses using variety or COA as even one of the independent variables, are only discussed in any detail below. All other pairings of independent variables, other than structure $\mathrm{x}$ variety, excluded both stem and leaf data for var. ' $T$ ' exclusively grown in the greenhouse, as these other analyses addressed independent variables only applicable to field grown material.

The generally preferred analysis in SAS for percentage data, at the time these analyses were run, was Compositional Analysis (John D. Reeve, personal communication, 2011). However, this would have required a larger number of data points than numbers of amino acids, so a full scale compositional analysis was not possible. Compositional analysis would have been possible for one or two amino acids at a time, if a larger number of individual data points had been available, even if only for at least one control organism. This was not the situation for the southern Illinois data, and not found for comparable data from other research on M. expansa or other crops compared to it (Kritzer Van Zant, 2017; Kritzer Van Zant et al., 2018, 2019). Utilizing a type of ANOVA called CANOVA (Canonical Analysis of Variance), which shares some aspects with regression, was also considered. Initially, CANOVA was run in SAS to compare means for differences among amino acids between varieties, between above and below ground portions of the plants, and for levels of organic amendments. The data was too unbalanced for the number of samples, to allow the CANOVA pro- 
grams to do more than analyze pairs of independent variables as ordinary ANOVAs, which is how it is reported. Had the same data been grouped for similar levels of amendments for both varieties, the subtle differences due to quantities of soil amendments within varieties would have been lost. In most cases, there would have been a control group vs a single all-inclusive treatment group. This is less useful than running each level separately. However, should larger scale growth trials become possible with $M$. expansa, compositional analysis and CANOVA may be possible, and are worthwhile statistical options to plan for.

\section{SI Results and Discussion}

\section{SI 1. Additional Details}

There were few data points for the M. expansa amino acid profile. Each data point represented a combination of plants from the same kinds of plots from different terraces or from the greenhouse (Kritzer Van Zant 2018). Therefore, two plot samples were combined for leaf, and two for root, for var. ' $L$ ' from the field, and two for var. ' $T$ ' root from the field, and one stem, and one leaf sample, for var. ' $T$ ' from the greenhouse, which were then submitted for amino acid profiling. The single enlarged var. ' $T$ ' stem sample produced above ground, though expected to be most similar to var. ' $T$ ' leaf, were most similar to roots of either variety for percentages of individual amino acids, CRDP (crude protein), and TOTP (total protein). This shows consistency for amino acid percentages within each variety, for all locations engorged with starch.

COA analyses only accounted for var. ' $L$ ' plots, including those having a combination of steer manure and peat, and all peat and all steer manure plots. However, additionally running the percentages of steer manure and peat inside COA plots as separate variables within the separate analyses for peat and steer manure, allowed us to examine all of the levels for each of these variables side-by-side for both varieties. Examination of the figures of graphs of the analyses in Appendix C-8 of Kritzer Van Zant (2016a), made it possible to visually compare how including or ignoring peat or steer manure from combined plots affected the outcomes, which gave some confidence in our interpretation of those results. As the largest differences for var. ' $L$ ' amino acids were usually for treated plots vs control plots, the inclusion of peat or steer manure separately, from the combined plots, was of less importance. Had the opposite been true these results would be less useful. Hopefully, these baseline results will be further studied in future research with fewer caveats for the data.

\section{SI 2. Tables of Positive ANOVA Results for all Amino Acids and Interactions}

ANOVA EXT Tables 1-10 of $M$. expansa $\mathrm{F}$ data gave the effects of independent field variables on percentages of amino acids. Interactions in these tables were for two independent variables with percentage of amino acids within subjects. Pvalues reported in the tables from these ANOVAs were cor- rected with the Huynh-Feldt-Lecoutre epsilon test of interaction. EXT Tables 11-20 were for results of the Tukey adjusted LS-Means analyses. The two sets of tables correlate with each other in their order of independent variables used for pair-wise comparisons. For example, EXT Table 1 was paired with EXT Table 11, and EXT Table 4 was paired with EXT Table 14, etc.

Tables that included variety as an independent variable (EXT Tables 1- 6, 11-16) had two levels, ' $L$ ' and ' $T$ '. Tables also included percentage of COA (EXT Tables 4, 7, 14, and 17). As there were many positive results, often conflicting for interpretation of the hypotheses, results and discussion of all pair-wise comparison analyses having variety and COA as independent variables were only discussed in the SI. Variety was included in the structure $\mathrm{x}$ variety comparisons for both ANOVAs (EXT Tables 1-3) and LS-Means (EXT Tables 11-13). As results were so similar, only results from EXT Tables 1 and 11, which were the most inclusive for data for EXT Tables 1-3, and for EXT Tables 11-13, were used for comparison to other data, though all six tables were mentioned in discussion. Discussion for COA or variety did not directly apply to any hypothesis.

In addition to the structure $\mathrm{x}$ variety analyses (EXT Tables 1-3, 11-13), remaining pairs of independent variables were variety x COA (EXT Tables 4,14$)$, variety x peat (EXT Tables 5 , 15 ), variety $x$ steer manure (EXT Tables 6,16 ), and structure $x$ COA (EXT Tables 7, 17), which includes peat and steer manure addressed individually, usually added alone to a plot though sometimes added to the same plot. Variable levels for these are: two for variety -var. ' $T$ ' and var. ' $L$ '; four for COA for field grown material of var. ' $L$ '- $0 \%$ COA, $3 \%$ peat, $1 \%$ peat with $3 \%$ steer manure, and $5 \%$ steer manure, and two for $\mathrm{COA}$ for field grown var. ' $T$ ' - $2 \%$ peat and $4 \%$ steer manure.

For COA, peat considered alone, and steer manure considered alone, there was no exact match for any of the variable levels between varieties so they must be understood along respective continuums of percentage.

Each of the structure $\mathrm{x}$ variety analyses included or excluded part or all of the var. ' $T$ ' data from the greenhouse-grown plants. When compared amongst themselves (EXT Tables 1-3), most results were the same. However, there were fewer results in the tables based on less raw data. Structure $\mathrm{x}$ variety Tukeyadjusted LS-Means t-values were given in the SI text below (EXT Tables 11-13).

For all three versions of the ANOVAs (EXT Tables 1-3) for structure $\mathrm{x}$ variety, including those with any greenhouse data for var. ' $T$ ', there were shifts in degrees of freedom and many of the $F$ and $p$ values, though there were very few changes in the degrees of significance. The few differences in the amount of significance were briefly described. EXT Table 2 had additional details on shifts in F's, p-values, and degrees of freedom for the structure $\mathrm{x}$ variety ANOVAs, also seen in graphs in Figs. 101-200 in Appendix C-8 of Kritzer Van Zant (2016a).

Differences between EXT Tables 1 and 2 were primarily between $f$-values and error terms for individual independent variables, though the degrees of significance were mostly the same, and p-values between EXT Tables 1 and 2 for variety and the interaction were nearly identical. Differences between the three structure $x$ variety ANOVA tables (EXT Tables 1-3) were 
further distinguished by the interaction.

\section{SI 2.1. Comparison of EXT Tables 1 and 2 for Differences in Structure}

TRP without the interaction term request for structure was significant in EXT Table $1\left(\mathrm{~F}=31.53_{2}, \mathrm{p}=0.0002\right)$ and highly significant in EXT Table $2\left(\mathrm{~F}=61.92_{1,8}, \mathrm{p}=<.0001\right)$, and dispensable GLU had the same results as TRP for structure. PRO with the interaction term request had significance for structure in EXT Table $1\left(\mathrm{~F}=5.86_{2,7}, \mathrm{p}=0.0319\right)$ and no significance in EXT Table 2.

\section{SI 2.2. Comparison of EXT Tables 1 and 2 for Differences in Variety}

In the structure $\mathrm{x}$ variety ANOVA analyses, with greenhouse leaf and stem data for var. ' $T$ ' (EXT Table 1) and with greenhouse leaf data and no stem for var. ' $T$ ' (EXT Table 2), without and with the interaction term request, there were no differences between the p-values for any dependent variable for variety.

\section{SI 2.3. Comparison of EXT Tables 1 and 2 for Differences in the Interaction}

In the structure $\mathrm{x}$ variety ANOVA analyses, with greenhouse leaf and stem data for var. ' $T$ ' (EXT Table 1) and with greenhouse leaf data and no stem for var. ' $T$ ' (EXT Table 2), without and with the interaction term request, there were no differences between the p-values for any dependent variable for the interaction.

\section{SI 2.4. Comparison of EXT Tables 1 and 3 for Differences in Structure}

TRP without the interaction term request was significant for structure $\left(\mathrm{F}=31.53_{2,8}, \mathrm{p}=0.0002\right)$ in EXT Table 1, though highly significant for structure $\left(\mathrm{F}=625.00_{1,7}, \mathrm{p}=<.0001\right)$ in EXT Table 3, and dispensable GLU without the interaction term request was also significant for structure $\left(\mathrm{F}=30.70_{2.8}, \mathrm{p}=\right.$ $0.00002)$ in EXT Table 1 though highly significant for structure in EXT Table $3\left(\mathrm{~F}=27.80_{1,7}, \mathrm{p}=0.0012\right)$.

\section{SI 2.5. Comparison of EXT Tables 1 and 3 for Differences in Variety}

Without the interaction term request, dispensable TAU (F $\left.=10.28_{1,8}, \mathrm{p}=0.0125\right)$ and TYR $\left(\mathrm{F}=8.45_{1,8}, \mathrm{p}=0.0197\right)$ were significant for variety in EXT Table 1, and not significant for the same in EXT Table 3.

His, without the interaction term request, was significant for variety in EXT Table $3\left(\mathrm{~F}=5.86_{1,7}, \mathrm{p}=0.0460\right)$ though not significant for the same in EXT Table 1, as was dispensable GLU.

ARG $\left(\mathrm{F}=51.84_{1,7}, \mathrm{p}=0.0002\right)$, ISO $\left(\mathrm{F}=37.08_{1,7}, \mathrm{p}=\right.$ $0.0005), \operatorname{LEU}\left(\mathrm{F}=39.95_{1,7}, \mathrm{p}=0.0004\right), \operatorname{LYS}\left(\mathrm{F}=5.74_{1,7}, \mathrm{p}=\right.$ 0.0477), $\operatorname{MET}\left(\mathrm{F}=27.73_{1,7}, \mathrm{p}=0.0012\right)$, THR $\left(\mathrm{F}=23.53_{1,7}, \mathrm{p}=\right.$ 0.0019), TRP ( $\left.F=49.00_{1,7}, p=0.0002\right)$ and VAL $\left(F=39.57_{1,7}, p\right.$
$=0.0004)$, as well as dispensable $\operatorname{ALA}\left(\mathrm{F}=8.94_{1,7}, \mathrm{p}=0.0202\right)$, $\operatorname{ASP}\left(\mathrm{F}=51.76_{1,7}, \mathrm{p}=0.0002\right), \operatorname{GLY}\left(\mathrm{F}=48.87_{1,7}, \mathrm{p}=0.0002\right)$, SER $\left(F=23.85_{1,7}, p=0.0018\right)$, TAU $\left(F=10.12_{1,7}, p=0.0154\right)$, and TOTP $\left(\mathrm{F}=34.99_{1,7}, \mathrm{p}=0.0006\right)$, with the interaction term request, were significant for variety in EXT Table 1 though not significant for the same in EXT Table 3.

PHE $\left(\mathrm{F}=100.50_{1,7}, \mathrm{p}=<.0001\right)$ and TYR $\left(\mathrm{F}=138.92_{1,7}, \mathrm{p}=\right.$ $<.0001$ ), with the interaction term request, were highly significant for variety in EXT Table 1 and not significant for the same in EXT Table 3.

\section{SI 2.6. Comparison of EXT Tables 1 and 3 for Differences in the Interaction}

Indispensable LEU $\left(\mathrm{F}=70.19_{1,7}, \mathrm{p}=<.0001\right)$, PHE $(\mathrm{F}=$ $\left.122.90_{1,7}, \mathrm{p}=<.0001\right)$, TRP $\left(\mathrm{F}=68.06_{1,7}, \mathrm{p}=<.0001\right)$, VAL ( $\mathrm{F}$ $\left.=63.10_{1,7}, \mathrm{p}=<.0001\right)$ as well as dispensable ASP $\left(\mathrm{F}=70.73_{1,7}\right.$, $\mathrm{p}=<.0001), \mathrm{GLU}\left(\mathrm{F}=92.11_{1,7} \mathrm{p}=<.0001\right), \mathrm{GLY}\left(\mathrm{F}=71.79_{1,7}\right.$, $\mathrm{p}=<.0001)$ and TYR $\left(\mathrm{F}=84.04_{1,7}, \mathrm{p}=<.0001\right)$, and TOTP $(\mathrm{F}$ $=68.60_{1,7}, \mathrm{p}=<.0001$ ), with the interaction term request, were highly significant for the interaction in EXT Table 1 though not significant for the same in EXT Table 3. Indispensable HIS (F $\left.=36.22_{1,7}, \mathrm{p}=0.0005\right)$, ISO $\left(\mathrm{F}=52.34_{1,7}, \mathrm{p}=0.0002\right)$, LYS $(\mathrm{F}$ $\left.=20.93_{1,7}, \mathrm{p}=0.0026\right)$, MET $\left(\mathrm{F}=41.43_{1,7}, \mathrm{p}=0.0004\right)$, THR $\left(\mathrm{F}=31.12_{1,7}, \mathrm{p}=0.0008\right)$ and dispensable $\operatorname{ALA}\left(\mathrm{F}=17.12_{1,7}, \mathrm{p}\right.$ $=0.0044), \operatorname{ASP}\left(\mathrm{F}=70.73_{1,7}, \mathrm{p}=<.0001\right), \mathrm{PRO}\left(\mathrm{F}=12.13_{1,7}\right.$, $\mathrm{p}=0.0102)$, and SER $\left(\mathrm{F}=21.49_{1,7}, \mathrm{p}=0.0024\right)$, and CRDP $(\mathrm{F}$ $=18.97_{1,7}, \mathrm{p}=0.0033$ ), with the interaction term request were significant for the interaction in EXT Table 1 though not significant in EXT Table 3.

\section{SI 2.7. Comparison of Structure $x$ Variety Analyses to Other Pair-wise Analyses}

Of the three structure $\mathrm{x}$ variety ANOVA analyses (EXT Tables 1-3), the version which includes leaf and stem var. ' $T$ ' data (EXT Table 1) was more informative and therefore of these three tables only EXT Table 1 positive results were presented in full in the SI above, and it was the only of the three (EXT Tables 1-3) used below for comparison with other pairings of independent variables which had included either structure or variety.

\section{SI 2.8. Positive Results for Structure in the Structure $x$ Variety ANOVAs with Greenhouse Leaf and Stem Data for var. ' $T$ '}

All positive results for structure for the indispensable amino acids and totals in the ANOVAs for the independent variables of structure $\mathrm{x}$ variety with no greenhouse data for var. ' $T$ ' (EXT Table 1) were without the interaction term request: highly significant for structure in ARG $\left(\mathrm{F}=146.20_{2,8}, \mathrm{p}=<.0001\right)$, HIS ( $\mathrm{F}$ $\left.=88.28_{2,8}, \mathrm{p}=<.0001\right)$, ISO $\left(\mathrm{F}=106.81_{2,8}, \mathrm{p}=<.0001\right)$, LEU ( $\mathrm{F}$ $\left.=132.28_{2,8}, \mathrm{p}=<.0001\right)$, LYS $\left(\mathrm{F}=243.28_{2,8}, \mathrm{p}=<.0001\right)$, MET $\left(\mathrm{F}=80.52_{2,8}, \mathrm{p}=<.0001\right)$, PHE $\left(\mathrm{F}=81.06_{2.8}, \mathrm{p}=<.0001\right)$, THR $\left(\mathrm{F}=171.48_{2,8}, \mathrm{p}=<.0001\right), \operatorname{VAL}\left(\mathrm{F}=61.92_{1,8}, \mathrm{p}=<.0001\right)$, $\mathrm{CRDP}\left(\mathrm{F}=60.12_{2.8}, \mathrm{p}=<.0001\right)$ and TOTP $\left(\mathrm{F}=76.21_{2,8}, \mathrm{p}=\right.$ $<.0001)$; and significant for TRP $\left(\mathrm{F}=31.53_{2,8}, \mathrm{p}=0.0002\right)$.

All positive results for structure for the indispensable amino 
acids and totals in the ANOVAs for the independent variables of structure $\mathrm{x}$ variety with no greenhouse data for var. ' $T$ ' (EXT Table 1) were with the interaction term request highly significant for: ARG ( $\left.\mathrm{F}=964.71_{2,7}, \mathrm{p}=<.0001\right)$; HIS $\left(\mathrm{F}=278.65_{2,7}, \mathrm{p}\right.$ $=<.0001)$; ISO $\left(\mathrm{F}=471.10_{2,7}, \mathrm{p}=<.0001\right)$; LEU $\left(\mathrm{F}=775.38_{2,7}\right.$, $\mathrm{p}=<.0001) ; \operatorname{LYS}\left(\mathrm{F}=552.51_{27}, \mathrm{p}=<.0001\right) ; \operatorname{MET}(\mathrm{F}=$ $280.73, \mathrm{p}=<.0001)$; PHE $(\mathrm{F}=749.60, \mathrm{p}=<.0001)$; THR (F $\left.=514.77_{27}, \mathrm{p}=<.0001\right) ; \mathrm{TRP}\left(\mathrm{F}=141.50_{27}, \mathrm{p}=<.0001\right)$; VAL $\left(\mathrm{F}=280.56_{1,7}, \mathrm{p}=<.0001\right) ; \mathrm{CRDP}\left(\mathrm{F}=110.12_{2,7}, \mathrm{p}=<.0001\right)$; and TOTP $\left(\mathrm{F}=407.95_{2,7}, \mathrm{p}=<.0001\right)$.

\section{SI 2.9. Positive Results for Variety in the Structure $x$ Variety ANOVAs with Greenhouse Leaf and Stem Data for var. 'T'}

All positive results for variety for the indispensable amino acids and totals in the ANOVAs for the independent variables of structure $\mathrm{x}$ variety with no greenhouse data for var. ' $T$ ' (EXT Table 1) were with the interaction term request: highly significant only for PHE $\left(\mathrm{F}=100.50_{1,7}, \mathrm{p}=<.0001\right)$; and significant for ARG $\left(F=51.84_{1,7}, p=0.0002\right)$, HIS $\left(F=9.32_{1,7}, p=0.0185\right)$, ISO $\left(F=37.08_{1,7}, p=0.0005\right)$, LEU $\left(F=39.95_{1,7}, p=0.0004\right)$, LYS $\left(\mathrm{F}=5.74_{1,7}, \mathrm{p}=0.0477\right)$, MET $\left(\mathrm{F}=27.73_{1,7}, \mathrm{p}=0.0012\right)$, THR $\left(\mathrm{F}=23.53_{1,7}, \mathrm{p}=0.0019\right)$, TRP $\left(\mathrm{F}=49.00_{1,7}, \mathrm{p}=0.0002\right)$, $\operatorname{VAL}\left(\mathrm{F}=49.00_{1,7}, \mathrm{p}=0.0002\right)$, and TOTP $\left(\mathrm{F}=34.99_{1,7}, \mathrm{p}=\right.$ 0.0006); though CRDP without and with the interaction term request was not significant for variety.

\section{SI 2.10. Positive Results for the interaction in the Structure $x$ Variety ANOVAs with Greenhouse Leaf and Stem Data for var. ' $T$ '}

All positive results for the interaction for the indispensable amino acids and totals in the ANOVAs for the independent variables of structure $\mathrm{x}$ variety with no greenhouse data for var. ' $T$ ' (EXT Table 1) were: highly significant for ARG $\left(\mathrm{F}=79.11_{1,7}, \mathrm{p}\right.$ $=<.0001), \operatorname{LEU}\left(\mathrm{F}=70.19_{1,7}, \mathrm{p}=<.0001\right)$, PHE $\left(\mathrm{F}=122.90_{1,7}\right.$, $\mathrm{p}=<.0001), \operatorname{TRP}\left(\mathrm{F}=68.06_{1,7}, \mathrm{p}=<.0001\right), \operatorname{VAL}\left(\mathrm{F}=68.06_{1,7}\right.$, $\mathrm{p}=<.0001)$, and TOTP $\left(\mathrm{F}=68.60_{1,7}, \mathrm{p}=<.0001\right)$; and significant for HIS ( $\left.\mathrm{F}=36.22_{1,7}, \mathrm{p}=0.0005\right)$, ISO $\left(\mathrm{F}=52.34_{1,7}, \mathrm{p}=\right.$ $0.0002)$, LYS $\left(\mathrm{F}=20.93_{1,7}, \mathrm{p}=0.0026\right)$, MET $\left(\mathrm{F}=41.43_{1,7}\right.$, $\mathrm{p}=0.0004)$, THR $\left(\mathrm{F}=31.12_{1,7}, \mathrm{p}=0.0008\right)$, and $\operatorname{CRDP}(\mathrm{F}=$ $\left.18.97_{1,7}, \mathrm{p}=0.0033\right)$.

Most amino acids in the structure $\mathrm{x}$ variety ANOVAs without a request for an interaction term, would have agreed with $\mathrm{H}_{0}$, had there been a similar hypothesis for variety to the hypotheses for structure, peat, and steer manure. This was true even though with the interaction term request the structure $\mathrm{x}$ variety ANOVAs had significance in agreement with $\mathrm{H}_{1}$ for variety. Despite this contradiction, these results are still worth discussing. This was because in the same analyses, both dispensable TAU and indispensable TYR were significant or highly significant without and with the interaction term request for variety. Therefore, a lack of significant results for variety without the interaction term request was not a uniform issue for every amino acid. This appears to indicate that these ANOVAs produced meaningful results for variety, without as well as with the interaction term request.
SI 2.11. Positive Results for Variety and for the Interaction, in the Variety $x$ Steer Manure ANOVAs with Greenhouse Leaf and Stem Data for var. ' $T$ '

Positive results for variety for the indispensable amino acids and totals in the ANOVA for the independent variables of variety $\mathrm{x}$ steer manure with no greenhouse data for var. ' $T$ ' (EXT Table 6) without the interaction term request, as well as for the interaction, were identical and significant only for dispensable HLY $\left(F=08.00_{1,5}, p=0.0367\right)$. There was no significance for the independent variable steer manure with or without the interaction term request, nor for variety with the interaction term request.

\section{SI 2.12. Positive Results for structure in the Structure $x \mathrm{COA}$ ANOVAs with no Greenhouse Data for var. ' $T$ '}

Positive results for structure for the indispensable amino acids and totals in the ANOVAs for the independent variables of structure x COA with no greenhouse data for var. ' $T$ ' (EXT Table 7) only without the interaction term request were: highly significant for ARG $\left(\mathrm{F}=2126.12_{1,3}, \mathrm{p}=<.0001\right)$, HIS ( $\mathrm{F}=$ $\left.2448.09_{1,3}, \mathrm{p}=<.0001\right)$, ISO ( $\left.\mathrm{F}=1437.48_{1,3}, \mathrm{p}=<.0001\right)$, LEU $\left(\mathrm{F}=1749.60_{1,3}, \mathrm{p}=<.0001\right)$, LYS $\left(\mathrm{F}=2980.12_{1,3}, \mathrm{p}=<.0001\right)$, MET $\left(\mathrm{F}=1046.29_{1,3}, \mathrm{p}=<.0001\right)$, PHE $\left(\mathrm{F}=1705.12_{1,3}, \mathrm{p}=\right.$ $<.0001)$, THR $\left(\mathrm{F}=961.00_{1,3}, \mathrm{p}=<.0001\right)$, VAL $\left(\mathrm{F}=1773.71_{1,3}\right.$, $\mathrm{p}=<.0001), \operatorname{CRDP}\left(\mathrm{F}=2049.44_{1,3}, \mathrm{p}=<.0001\right)$ and TOTP $(\mathrm{F}$ $\left.=1980.51_{1,3}, \mathrm{p}=<.0001\right)$; and significant only for TRP $(\mathrm{F}=$ $\left.535.71_{1,3}, \mathrm{p}=0.0002\right)$.

\section{SI 2.13. Positive Results for $\mathrm{COA}$ in the Structure $x \mathrm{COA}$ ANOVAs with no Greenhouse Data for var. ' $T$ '}

Positive results for COA for the indispensable amino acids and totals in the ANOVAs for the independent variables of structure x COA with no greenhouse data for var. ' $T$ ' (EXT Table 7) was significant only for CRDP and only without the interaction term request $\left(\mathrm{F}=11.54_{5,3}, \mathrm{p}=0.0357\right)$, though there were no positive results in the LS-Means analyses for the same pair of independent variables (EXT Table 17; see SI 3.6), and in spite of several positive results in the same ANOVA analyses for structure (EXT Table 7).

\section{SI 2.14. Results for the Interaction in the Structure $x \mathrm{COA}$ ANOVAs with no Greenhouse Data for var. ' $T$ '}

Results for the interaction for the indispensable amino acids and totals in the ANOVAs for the independent variables of structure x COA with no greenhouse data for var. ' $T$ ' (EXT Table 7) with the interaction term request were not significant.

\section{SI 2.15. Positive Results for the Interaction in the Structure $x$ Peat ANOVAs with no Greenhouse Data for var. ' $T$ '}

Positive results for the Interaction for peat for the indispensable amino acids and totals in the ANOVAs for the independent variables of structure $\mathrm{x}$ peat with no greenhouse data for var. 
' $\mathrm{T}$ ' (EXT Table 8$)$ was only significant for MET $\left(\mathrm{F}=25.30_{2,3}\right.$, $\mathrm{p}=0.0132)$.

\section{SI 2.16. Results for the Interaction, in the Structure $x$ Steer Manure and Peat $x$ Steer Manure ANOVAs, each with no Greenhouse Data for var. ' $T$ '}

There were no positive results in the ANOVAs for the interaction, from the structure by steer manure (EXT Table 9) or peat $\mathrm{x}$ steer manure (EXT Table 10) ANOVAs. These analyses both excluded greenhouse data for var. ' $T$ '. EXT Table 9 had positive results for both individual independent variables though EXT Table 10 did not. Tukey-adjusted LS-Means analyses of both pair-wise comparisons, also had positive results (EXT Tables 19, 20).

\section{SI 2.17. ANOVA Tables Named in Discussion not Containing Significant Data}

There were no positive results with or without the request for the interaction term, from the variety x COA (EXT Table 4), variety x peat (EXT Table 5), or peat $\mathrm{x}$ steer manure (EXT Table 10) ANOVAs. Distribution of negative and uncomputed results in EXT Tables 4, 5 and 10 are available in Appendix C-7 of Kritzer Van Zant (2016a). SI ANOVA Tables 4, 5 and 10 correlate consecutively with SI LS-Means Tables 14, 15 and 20 for the consecutively same pair-wise comparisons, which all have positive results presented below. All other positive ANOVA data was discussed in the text of the main paper above, so was not detailed again in discussion in the SI.

SI 3. EXT Tables 11-20 Tukey Adjusted LS-Means of M. expansa Data; Effects of Independent Field Variable Levels on Percentages of Amino Acids

EXT Tables 11-20 showed positive data for the Tukey adjusted LS-Means T-table data with levels for the same variables seen in ANOVA EXT Tables 1-10, and matched to them in the order in which dependent variables were presented for each pair-wise comparison. Supporting LS-Means tables were presented in this form to save white space, fit into a standard Word document, and for easier comparison with text description. Excel formatted tables of the same LS-Means data were also previously given (Kritzer Van Zant 2016a).

\section{SI 3.1. Comparison of Structure $x$ Variety LS-Means Analyses}

Structure $\mathrm{x}$ variety were run in the Tukey-adjusted LSMeans analyses incorporating data from the field grown plants, and also incorporating both leaf and stem data for var. ' $T$ ' from greenhouse-grown plants (EXT Table 11), and then only also additionally incorporating the var. ' $T$ ' leaf data (EXT Table 12), and finally with only field data while excluding the greenhouse data (EXT Table 13). Differences among the results from the three versions of the structure $\mathrm{x}$ variety LS-Means analyses, mostly consisted of shifts in the assigned Tukey-Kramer letters, as consecutively fewer variable level combinations were included as more data was excluded. Relative assignments of Tukey-Kramer letters did not lose relative meaning among level combinations in the structure $\mathrm{x}$ variety LS-Means analyses as data was excluded. There were also some slight differences in assigned Tukey-Kramer letters among the structure $\mathrm{x}$ variety LS-Means t-values, after changes were made to the rounding of all final digits after the decimal 5 , from rounding up to rounding down (EXT Tables 11-13). Structure x variety ANOVA F-values were given above (EXT Table 1), also representing data for EXT Tables 2 and 3, which were for the same pair-wise comparison as EXT Table 1. However, EXT Table 2 was based on the same data as EXT Table 1, including green-house leaf data for var. ' $T$ ' though lacking greenhouse stem data for var. ' $T$ '. EXT Table 3 lacked all of the green-house data for var. ' $T$ '. The same was true for the consecutively matching Tukey-adjusted LS-Means analyses (EXT Tables 11, 12 and 13), so of these three versions of the structure $\mathrm{x}$ variety LS-Means analyses, only fully or partially positive results for level combinations for the independent variables from EXT Table 11, are detailed in full below.

\section{SI 3.2. Positive Results in the Structure $x$ Variety $L S$-Means with Greenhouse Leaf and Stem Data Included for var. ' $T$ '}

Positive results for the indispensable amino acids and totals in the Tukey-adjusted LS-Means analyses for the independent variables of structure $\mathrm{x}$ variety with greenhouse data for var. 'T' (EXT Table 11) were: ARG highly significant for all variable level combinations which included var. ' $L$ ' root 0.23 $\pm 0.01_{C}{ }^{* *}$, var. ' $T$ ' $\operatorname{root} 0.27 \pm 0.02_{C}{ }^{* *}$, var. ' $T$ ' stem $00.27 \pm$ $0.03_{\mathrm{C}}{ }^{* *}$, var. ' $T$ ' leaf $0.99 \pm 0.03_{\mathrm{B}}{ }^{* *}$, and var. ' $L$ ' leaf $1.32 \pm$ $0.01_{\mathrm{A}}^{* *}$; HIS highly significant for all variable level combinations which included var. ' $L$ ' root $0.13 \pm 0.01_{\mathrm{C}}{ }^{* *}$, var. ' $T$ ' stem $00.15 \pm 0.02_{C}{ }^{* *}$, var. ' $T$ ' root $0.17 \pm 0.01_{C}{ }^{* *}$, var. ' $T$ ' leaf 0.42 $\pm 0.02_{\mathrm{B}}{ }^{* *}$ and var. ' $L$ ' leaf $0.55 \pm 0.01_{\mathrm{A}}^{* *}$; ISO highly significant for all level combinations which included var. ' $L$ ' root 0.25 $\pm 0.02_{\mathrm{C}}{ }^{* *}$, var. ' $T$ ' stem $00.26 \pm 0.03_{\mathrm{C}}{ }^{* *}$, var. ' $T$ ' root $0.28 \pm$ $0.02_{\mathrm{C}}{ }^{* *}$, var. ' $T$ ' leaf $0.84 \pm 0.03_{\mathrm{B}}{ }^{* *}$, and var. ' $L$ ' leaf $1.16 \pm$ $0.02_{\mathrm{A}}^{* * ;}$, LEU highly significant for all variable level combinations which included var. ' $L$ ' root $0.37 \pm 0.02_{\mathrm{C}}{ }^{* *}$; var. ' $T$ ' root $0.44 \pm 0.03_{\mathrm{C}}{ }^{* *}$; var. ' $T$ ' stem $0.45 \pm 0.05_{\mathrm{C}}{ }^{* *}$; var. ' $T$ ' leaf 1.49 $\pm 0.05_{\mathrm{B}}{ }^{* *}$; var. ' $L$ ' leaf $1.99 \pm 0.02_{\mathrm{A}}{ }^{* *}$ ); LYS highly significant for all variable level combinations which included var. ' $L$ ' root $0.37 \pm 0.02_{C}{ }^{* *}$, var. ' $T$ ' stem $0.41 \pm 0.04{ }_{C}{ }^{* *}$, var. ' $T$ ' root 0.43 $\pm 0.03_{\mathrm{C}}{ }^{* *}$, var. ' $T$ ' leaf $1.25 \pm 0.04_{\mathrm{B}}{ }^{* *}$ and var. ' $L$ ' leaf $1.45 \pm$ $0.02^{* *}$; MET highly significant or significant for var. ' $L$ ' root $0.10 \pm 0.01_{C}^{* *}$, var. ' $T$ ' stem $0.11 \pm 0.02_{C}{ }^{*}$, var. ' $T$ ' root 0.12 $\pm 0.01_{\mathrm{C}}{ }^{* *}$, var. ' $T$ ' leaf $0.34 \pm 0.02_{\mathrm{B}}{ }^{* *}$ and var. ' $L$ ' leaf $0.49 \pm$ $0.01_{\mathrm{A}}^{* *}$; PHE highly significant for all variable level combinations which included var. ' $L$ ' root $0.24 \pm 0.02_{C}{ }^{* *}$, var. ' $T$ ' root $0.27 \pm 0.02_{\mathrm{C}}{ }^{* *}$, var. ' $T$ ' stem $0.29 \pm 0.03_{\mathrm{C}}{ }^{* *}$, var. ' $T$ ' leaf $0.92 \pm$ $0.03_{\mathrm{B}}{ }^{* *}$ and var. ' $L$ ' leaf $1.42 \pm 0.02_{\mathrm{A}}{ }^{* *}$; THR highly significant for all variable level combinations which included var. ' $L$ ' root $0.27 \pm 0.01_{\mathrm{C}}{ }^{* *}$, var. ' $T$ ' root $0.28 \pm 0.02_{\mathrm{C}}{ }^{* *}$, var. ' $T$ ' stem 0.32 $\pm 0.03_{\mathrm{C}}{ }^{* *}$, var. ' $T$ ' leaf $0.83 \pm 0.03_{\mathrm{B}}{ }^{* *}$ and var. ' $L$ ' leaf $1.04 \pm$ $0.01_{\mathrm{A}}^{* *}$; TRP highly significant or significant for all variable level combinations which included var. ' $T$ ' stem $0.04 \pm 0.01_{\mathrm{C}}{ }^{*}$, 
var. ' $L$ ' root $0.05 \pm 0.01_{\mathrm{C}}^{* *}$, var. ' $T$ ' root $0.06 \pm 0.01_{\mathrm{C}}{ }^{*}$, var. ' $T$ ' leaf $0.15 \pm 0.01_{\mathrm{B}}^{* *}$ and var. ' $L$ ' leaf $0.30 \pm 0.01_{\mathrm{A}}^{* *}$; VAL highly significant for all variable level combinations which included var. ' $L$ ' root $0.30 \pm 0.02_{\mathrm{C}}{ }^{* *}$, var. ' $T$ ' stem $0.33 \pm 0.04_{\mathrm{C}}^{* *}$, var. ' $T$ ' root $0.35 \pm 0.03_{\mathrm{C}}^{* *}$, var. ' $T$ ' leaf $1.01 \pm 0.04_{\mathrm{B}}{ }^{* *}$ and var. ' $L$ ' leaf $1.40 \pm 0.02_{\mathrm{A}}^{* *}$; CRDP highly significant or significant for all variable level combinations which included stem of var. ' $T$ ' $8.78 \pm 1.52_{\mathrm{C}}^{*}$, root of var. ' $L$ ' $8.89 \pm 0.76_{\mathrm{C}}^{* *}$, root of var. ' $T$ ' $11.42 \pm 1.08_{\mathrm{C}}^{* *}$, leaf of var. ' $T$ ' $22.52 \pm 1.52_{\mathrm{B}}^{* *}$ and leaf of var. ' $L$ ' $29.37 \pm 0.76_{\mathrm{A}}^{* *}$; and TOTP highly significant for all variable level combinations which included root for var. ' $L$ ' $5.70 \pm$ $0.35_{\mathrm{C}}{ }^{* *}$, stem for var. ' $T$ ' $5.99 \pm 0.70_{\mathrm{C}}{ }^{* *}$, root for var. ' $T$ ' 6.87 $\pm 0.49_{\mathrm{C}}{ }^{* *}$, leaf for var. ' $T$ ' $16.80 \pm 0.70_{\mathrm{B}}{ }^{* *}$ and leaf for var. ' $L$ ' $23.80 \pm 0.35_{\mathrm{A}}^{* *}$.

\section{SI 3.3. Positive Results in the Structure x Peat LS-Means with no Greenhouse Data for var. ' $T$ '}

Positive results for the indispensable amino acids and totals in the Tukey-adjusted LS Means analyses for structure $\mathrm{x}$ peat with no greenhouse data for var. ' $T$ ' (EXT Table 18) were: ARG was highly significant for leaf and significant for root for all variable level combinations which included: $0 \%$ peat for root $0.23 \pm 0.02_{\mathrm{B}}^{*}, 1 \%$ peat for root $0.24 \pm 0.03_{\mathrm{B}}^{*}, 3 \%$ peat for root $0.26 \pm 0.03_{\mathrm{B}} *, 2 \%$ peat for root $0.28 \pm 0.03_{\mathrm{B}}^{*}, 3 \%$ peat for leaf $1.28 \pm 0.03_{\mathrm{A}}^{* *}, 0 \%$ peat for leaf $1.32 \pm 0.02_{\mathrm{A}}^{* *}$ and $1 \%$ peat for leaf $1.36 \pm 0.03_{\mathrm{A}}^{* *}$; HIS with no greenhouse data for var. ' $T$ ' was highly significant for leaf and significant for root for all variable level combinations which included $0 \%$ peat for root $0.13 \pm 0.01_{\mathrm{B}}^{*}, 1 \%$ peat for root $0.13 \pm 0.01_{\mathrm{B}} *, 3 \%$ peat for root $0.13 \pm 0.01_{\mathrm{B}}^{*}, 2 \%$ peat for root $0.20 \pm 0.01_{\mathrm{B}}^{*}, 3 \%$ peat for leaf $0.53 \pm 0.01_{\mathrm{A}}^{* *}, 0 \%$ peat for leaf $0.55 \pm 0.01_{\mathrm{A}}^{* *}$ and $1 \%$ peat for leaf $0.57 \pm 0.01_{\mathrm{A}}^{* *}$; ISO was highly significant for leaf and significant for root for all variable level combinations which included $0 \%$ peat for root $0.25 \pm 0.01_{\mathrm{B}} *, 1 \%$ peat for root 0.25 $\pm 0.02_{\mathrm{B}}^{*}, 3 \%$ peat for root $0.27 \pm 0.02_{\mathrm{B}}^{*}, 2 \%$ peat for root 0.31 $\pm 0.02_{\mathrm{B}}^{*}, 3 \%$ peat for leaf $1.11 \pm 0.02_{\mathrm{A}}^{* *}, 0 \%$ peat for leaf 1.16 $\pm 0.02_{\mathrm{A}}^{* *}$ and $1 \%$ peat for leaf $1.20 \pm 0.02_{\mathrm{A}}^{* *}$; LEU was highly significant for leaf and significant for root for all variable level combinations which included $0 \%$ peat for root $0.37 \pm 0.02_{\mathrm{B}}{ }^{*}$, $1 \%$ peat for root $0.38 \pm 0.04_{\mathrm{B}}{ }^{*}, 3 \%$ peat for root $0.39 \pm 0.04{ }_{\mathrm{B}}^{*}$, $2 \%$ peat for root $0.47 \pm 0.04_{\mathrm{B}}^{*}, 3 \%$ peat for leaf $1.90 \pm 0.04_{\mathrm{A}} * *$, $0 \%$ peat for leaf $2.01 \pm 0.03^{* *}$ and $1 \%$ peat for leaf $2.03 \pm$ $0.04_{\mathrm{A}}^{* *}$; LYS was highly significant for leaf and significant for root for all variable level combinations which included $0 \%$ peat for root $0.37 \pm 0.02_{\mathrm{B}}{ }^{*}, 1 \%$ peat for root $0.38 \pm 0.03_{\mathrm{B}}{ }^{*}, 3 \%$ peat for root $0.39 \pm 0.03_{\mathrm{B}}^{*}, 2 \%$ peat for root $0.49 \pm 0.03_{\mathrm{B}}^{*}, 3 \%$ peat for leaf $1.41 \pm 0.03_{\mathrm{A}}^{* *}, 0 \%$ peat for leaf $1.46 \pm 0.02_{\mathrm{A}}^{* *}$ and $1 \%$ peat for leaf $1.47 \pm 0.03_{\mathrm{A}}^{* *}$; MET was highly significant for all variable level combinations for both leaf and root, which included $0 \%$ peat for root $0.10 \pm 0.00_{\mathrm{D}}^{* *}, 1 \%$ peat for root 0.11 $\pm 0.00_{\mathrm{CD}} * *, 3 \%$ peat for root $0.11 \pm 0.00_{\mathrm{CD}} * *, 2 \%$ peat for root $0.14 \pm 0.00_{\mathrm{C}}^{* *}, 3 \%$ peat for leaf $0.46 \pm 0.00_{\mathrm{B}}^{* *}, 0 \%$ peat for leaf $0.49 \pm 0.00_{\mathrm{A}}^{* *}$ and $1 \%$ peat for leaf $0.51 \pm 0.00_{\mathrm{A}}^{* *}$; PHE in the LS-Means analyses for structure $\mathrm{x}$ peat with no greenhouse data for var. ' $T$ ' (EXT Table 18), was highly significant for leaf and significant for root for all variable level combina- tions which included $0 \%$ peat for root $0.24 \pm 0.01_{\mathrm{B}}^{*}, 1 \%$ peat for root $0.24 \pm 0.02_{\mathrm{B}}^{*}, 3 \%$ peat for root $0.27 \pm 0.02_{\mathrm{B}}^{*}, 2 \%$ peat for root $0.29 \pm 0.022_{\mathrm{B}}^{*}, 3 \%$ peat for leaf $1.36 \pm 0.02_{\mathrm{A}}^{* *}, 0 \%$ peat for leaf $1.42 \pm 0.01_{\mathrm{A}}^{* *}$ and $1 \%$ peat for leaf $1.46 \pm 0.02_{\mathrm{A}}^{* *}$; THR was highly significant for leaf and significant for root for all variable level combinations which included $0 \%$ peat for root $0.26 \pm 0.01_{\mathrm{B}}{ }^{*}, 1 \%$ peat for root $0.27 \pm 0.02_{\mathrm{B}}{ }^{*}, 3 \%$ peat for root $0.30 \pm 0.02_{\mathrm{B}}{ }^{*}, 2 \%$ peat for root $0.31 \pm 0.02_{\mathrm{B}}{ }^{*}, 3 \%$ peat for leaf $1.01 \pm 0.02_{\mathrm{A}}^{* *}, 1 \%$ peat for leaf $1.04 \pm 0.02_{\mathrm{A}}^{* *}$ and $0 \%$ peat for leaf $1.06 \pm 0.01_{\mathrm{A}}^{* *}$; TRP was highly significant or significant for all variable level combinations which included $0 \%$ peat for root $0.05 \pm 0.01_{\mathrm{B}}{ }^{*}, 1 \%$ peat for root $0.05 \pm 0.01_{\mathrm{B}}^{*}, 3 \%$ peat for root $0.05 \pm 0.01_{\mathrm{B}}^{*}, 2 \%$ peat for root $0.08 \pm 0.01_{\mathrm{B}}^{*}, 0 \%$ peat for leaf $0.29 \pm 0.01_{\mathrm{A}}^{* *}, 3 \%$ peat for leaf $0.31 \pm 0.01_{\mathrm{A}}^{* *}$ and $1 \%$ peat for leaf $0.32 \pm 0.01_{\mathrm{A}}^{* *}$; VAL was highly significant for leaf and significant for root for all variable level combinations which included $0 \%$ peat for root $0.30 \pm 0.02_{\mathrm{B}}{ }^{*}, 1 \%$ peat for root $0.31 \pm 0.03_{\mathrm{B}}{ }^{*}, 2 \%$ peat for root $0.38 \pm 0.03_{\mathrm{B}}{ }^{*}, 3 \%$ peat for root $0.32 \pm 0.03_{\mathrm{B}}^{*}, 0 \%$ peat for leaf $1.40 \pm 0.02_{\mathrm{A}}^{* *}, 1 \%$ peat for leaf $1.44 \pm 0.03_{\mathrm{A}}^{* *}$ and $3 \%$ peat for leaf $1.34 \pm 0.03_{\mathrm{A}}^{* *}$; CRDP was highly significant for leaf and significant for root for all variable level combinations which included $0 \%$ peat for root $8.64 \pm$ $0.56_{\mathrm{B}}{ }^{*}, 3 \%$ peat for root $9.25 \pm 0.96_{\mathrm{B}}^{*}, 1 \%$ peat for root $9.31 \pm$ $0.96_{\mathrm{B}}^{*}, 2 \%$ peat for root $13.91 \pm 0.96_{\mathrm{B}}{ }^{*}, 3 \%$ peat for leaf 28.70 $\pm 0.96_{\mathrm{A}}^{* *}, 1 \%$ peat for leaf $29.43 \pm 0.96_{\mathrm{A}} * *$ and $0 \%$ peat for leaf $29.68 \pm 0.68 * *$; and TOTP for variable level combinations was highly significant for leaf and one of four root results, and significant for three of four root, which included $0 \%$ peat for $\operatorname{root} 5.62 \pm 0.20_{\mathrm{B}} * *, 3 \%$ peat for root $5.94 \pm 0.35_{\mathrm{B}}{ }^{*}, 1 \%$ peat for $\operatorname{root} 5.98 \pm 0.35_{\mathrm{B}}^{*}, 2 \%$ peat for root $7.76 \pm 0.35_{\mathrm{B}}^{*}, 3 \%$ peat for leaf $22.84 \pm 0.35_{\mathrm{A}}^{* *}, 0 \%$ peat for leaf $23.97 \pm 0.25_{\mathrm{A}}^{* *}$ and $1 \%$ peat for leaf $24.43 \pm 0.35_{\mathrm{A}}^{* *}$.

\section{SI 3.4. Positive Results in the Structure $x$ Steer Manure LS- Means with no Greenhouse Data for var. ' $T$ '}

Positive results for the indispensable amino acids and totals in the Tukey-adjusted LS Means analyses for structure x steer manure with no greenhouse data for var. ' $T$ ' (EXT Table 19) were: ARG was highly significant for leaf or significant for root for all variable level combinations which included 5\% steer manure for root $0.23 \pm 0.03_{\mathrm{B}}{ }^{*}, 3 \%$ steer manure for root 0.24 $\pm 0.03_{\mathrm{B}}{ }^{*}, 0 \%$ steer manure for root $0.25 \pm 0.02_{\mathrm{B}}{ }^{*}, 4 \%$ steer manure for root $0.26 \pm 0.03_{\mathrm{B}}{ }^{*}, 0 \%$ steer manure for leaf 1.29 $\pm 0.02_{\mathrm{A}}^{* *}, 5 \%$ steer manure for leaf $1.35 \pm 0.03_{\mathrm{A}}^{* *}$ and $3 \%$ steer manure for leaf $1.36 \pm 0.03_{\mathrm{A}}^{* *}$; HIS was significant for all variable level combinations which included 3\% steer manure for root $0.13 \pm 0.03_{\mathrm{B}}{ }^{*}, 5 \%$ steer manure for root $0.13 \pm 0.03_{\mathrm{B}}{ }^{*}$, $4 \%$ steer manure for root $0.14 \pm 0.03_{\mathrm{B}}{ }^{*}, 0 \%$ steer manure for root $0.15 \pm 0.02_{\mathrm{B}}^{*}, 0 \%$ steer manure for leaf $0.53 \pm 0.02_{\mathrm{A}}^{*}, 5 \%$ steer manure for leaf $0.56 \pm 0.03_{\mathrm{A}}^{*}$ and $3 \%$ steer manure for leaf $0.57 \pm 0.03_{\mathrm{A}}^{*}$; ISO was highly significant or significant for all variable level combinations which included 3\% steer manure for root $0.25 \pm 0.03_{\mathrm{B}}{ }^{*}, 4 \%$ steer manure for root 0.25 $\pm 0.03_{\mathrm{B}}{ }^{*}, 5 \%$ steer manure for root $0.26 \pm 0.03_{\mathrm{B}}{ }^{*}, 0 \%$ steer manure for root $0.27 \pm 0.02_{\mathrm{B}}^{*}, 0 \%$ steer manure for leaf $1.12 \pm$ $0.02_{\mathrm{A}}^{* *}, 5 \%$ steer manure for leaf $1.19 \pm 0.03_{\mathrm{A}}^{* *}$ and $3 \%$ steer 
manure for leaf $1.20 \pm 0.03_{\mathrm{A}}{ }^{* *}$; LEU was highly significant for leaf or significant for root for all variable level combinations which included $5 \%$ steer manure for root $0.36 \pm 0.06_{\mathrm{B}}{ }^{*}$, $3 \%$ steer manure for root $0.38 \pm 0.06_{\mathrm{B}}{ }^{*}, 0 \%$ steer manure for root $0.40 \pm 0.03_{\mathrm{B}}{ }^{*}, 4 \%$ steer manure for root $0.41 \pm 0.06_{\mathrm{B}}{ }^{*}, 0 \%$ steer manure for leaf $1.94 \pm 0.04_{\mathrm{A}}^{* *}, 3 \%$ steer manure for leaf $2.03 \pm 0.06_{\mathrm{A}}^{* *}$ and $5 \%$ steer manure for leaf $2.05 \pm 0.06_{\mathrm{A}}^{* *}$; LYS for variable level combinations was highly significant for one of three and significant for two of three leaf, and significant for all of three root, which included $3 \%$ steer manure for root $0.38 \pm 0.06_{\mathrm{B}}{ }^{*}, 4 \%$ steer manure for root $0.38 \pm 0.06_{\mathrm{B}}{ }^{*}$, $5 \%$ steer manure for root $0.38 \pm 0.06_{\mathrm{B}}{ }^{*}, 0 \%$ steer manure for root $0.41 \pm 0.04_{\mathrm{B}}{ }^{*}, 0 \%$ steer manure for leaf $1.42 \pm 0.04_{\mathrm{A}}^{* *}$, $3 \%$ steer manure for leaf $1.47 \pm 0.06_{\mathrm{A}}^{*}$ and $5 \%$ steer manure for leaf $1.49 \pm 0.06^{*}$; MET for variable level combinations was highly significant for one and significant for two of three levels of leaf, and was significant for four of four levels of root, which included $4 \%$ steer manure for root $0.10 \pm 0.02_{\mathrm{B}} *, 5 \%$ steer manure for root $0.10 \pm 0.02_{\mathrm{B}}{ }^{*}, 3 \%$ steer manure for root $0.11 \pm 0.02_{\mathrm{B}}{ }^{*}, 0 \%$ steer manure for root $0.12 \pm 0.01_{\mathrm{B}}{ }^{*}, 0 \%$ steer manure for leaf $0.47 \pm 0.01_{\mathrm{A}}^{* *}, 5 \%$ steer manure for leaf 0.50 $\pm 0.02_{\mathrm{A}}^{*}$ and $3 \%$ steer manure for leaf $0.51 \pm 0.02_{\mathrm{A}}^{*}$; PHE was highly significant for leaf and significant for root for all variable level combinations which included 3\% steer manure for root $0.24 \pm 0.03_{\mathrm{B}}{ }^{*}, 4 \%$ steer manure for root $0.25 \pm 0.03_{\mathrm{B}}{ }^{*}, 5 \%$ steer manure for root $0.25 \pm 0.03_{\mathrm{B}}{ }^{*}, 0 \%$ steer manure for root $0.26 \pm$ $0.02_{\mathrm{B}}^{*}, 0 \%$ steer manure for leaf $1.38 \pm 0.02_{\mathrm{A}}^{* *}, 5 \%$ steer manure for leaf $1.44 \pm 0.03_{\mathrm{A}}^{* *}$ and $3 \%$ steer manure for leaf 1.46 $\pm 0.03_{\mathrm{A}}{ }^{* *}$; THR was highly significant for leaf and significant for root for all variable level combinations which included $4 \%$ steer manure for root $0.26 \pm 0.03_{\mathrm{B}}{ }^{*}, 5 \%$ steer manure for root $0.26 \pm 0.03_{\mathrm{B}}{ }^{*}, 3 \%$ steer manure for root $0.27 \pm 0.03_{\mathrm{B}}{ }^{*}, 0 \%$ steer manure for root $0.29 \pm 0.02_{\mathrm{B}}{ }^{*}, 0 \%$ steer manure for leaf 1.02 $\pm 0.02 * *, 3 \%$ steer manure for leaf $1.04 \pm 0.03 * *$ and $5 \%$ steer manure for leaf $1.09 \pm 0.03_{\mathrm{A}}^{* *}$; TRP for variable level combinations was highly significant for one and significant for two of three leaf and significant for four of four root results, which included 3\% steer manure for root $0.05 \pm 0.01_{\mathrm{B}} * 4 \%$ steer manure for root $0.05 \pm 0.01_{\mathrm{B}}{ }^{*}, 5 \%$ steer manure for root $0.06 \pm 0.01_{\mathrm{B}}{ }^{*}, 0 \%$ steer manure for root $0.06 \pm 0.01_{\mathrm{B}}{ }^{*}, 5 \%$ steer manure for leaf $0.28 \pm 0.01_{A}^{*}, 0 \%$ steer manure for leaf 0.30 $\pm 0.01_{\mathrm{A}}^{* *}$ and $3 \%$ steer manure for leaf $0.32 \pm 0.01_{\mathrm{A}}^{*}$; VAL was highly significant for leaf and significant for root for all variable level combinations which included $3 \%$ steer manure for root $0.31 \pm 0.04_{\mathrm{B}}{ }^{*}, 5 \%$ steer manure for root $0.31 \pm 0.04_{\mathrm{B}}{ }^{*}$, $4 \%$ steer manure for root $0.32 \pm 0.04_{\mathrm{B}}{ }^{*}, 0 \%$ steer manure for root $0.33 \pm 0.02_{\mathrm{B}}{ }^{*}, 0 \%$ steer manure for leaf $1.35 \pm 0.03_{\mathrm{A}}{ }^{* *}$, $3 \%$ steer manure for leaf $1.44 \pm 0.04 * *$ and $5 \%$ steer manure for leaf $1.44 \pm 0.04_{\mathrm{A}}{ }^{* *}$; CRDP was significant for all variable level combinations, which included $4 \%$ steer manure for root $8.94 \pm 2.58_{\mathrm{A}}{ }^{*}, 5 \%$ steer manure for root $9.11 \pm 2.58_{\mathrm{A}}{ }^{*}, 3 \%$ steer manure for root $9.31 \pm 2.58_{\mathrm{A}}{ }^{*}, 0 \%$ steer manure for root 10.35 $\pm 1.49{ }_{\mathrm{A}}^{*}, 0 \%$ steer manure for leaf $28.70 \pm 1.82_{\mathrm{A}}^{*}, 3 \%$ steer manure for leaf $29.43 \pm 2.58_{\mathrm{A}}^{*}$ and $5 \%$ steer manure for leaf $30.66 \pm 2.58_{\mathrm{A}}{ }^{*}$; and TOTP for variable level combinations was highly significant for one and significant for two of three leaf, and significant for four of four root, which included 5\% steer manure for root $5.55 \pm 1.09_{\mathrm{B}}{ }^{*}, 3 \%$ steer manure for root 5.98 $\pm 1.09{ }_{\mathrm{B}}^{*}, 4 \%$ steer manure for root $5.98 \pm 1.09_{\mathrm{B}}^{*}, 0 \%$ steer manure for root $6.35 \pm 0.63_{\mathrm{B}^{*}}, 0 \%$ steer manure for leaf $23.26 \pm$ $0.77_{\mathrm{A}}^{* *}, 5 \%$ steer manure for leaf $24.25 \pm 1.09_{\mathrm{A}}^{*}$ and $3 \%$ steer manure for leaf $24.43 \pm 1.09 *$.

\section{SI 3.5. Positive Results in the Peat x Steer Manure LS-Means with no Greenhouse Data for var. ' $T$ '}

There were no positive results for any of the indispensable amino acids and totals in the Tukey-adjusted LS Means for peat $\mathrm{x}$ steer manure with no greenhouse data for var. ' $T$ ' (EXT Table 20). For peat $x$ steer manure significant results were only found for dispensable amino acids HLY, HPR, PRO and TAU. Of these, only HLY was significant for all variable level combinations.

Positive results for the dispensable amino acids in the Tukeyadjusted LS Means for peat $\mathrm{x}$ steer manure with no greenhouse data for var. ' $T$ ' (EXT Table 20) were: HLY was significant for independent variable level combinations $0 \%$ peat and $0 \%$ steer manure $0.15 \pm 0.02_{\mathrm{A}}^{*}, 2 \%$ peat and $0 \%$ steer manure $0.24 \pm$ $0.03 *, 3 \%$ peat and $0 \%$ steer manure $0.14 \pm 0.02_{\mathrm{A}}^{*}, 1 \%$ peat and $3 \%$ steer manure $0.13 \pm 0.02_{\mathrm{A}}^{*}, 0 \%$ peat and $4 \%$ steer manure $0.13 \pm 0.03_{\mathrm{A}}^{*}, 0 \%$ peat and $5 \%$ steer manure $0.12 \pm 0.02_{\mathrm{A}}^{*}$; HPR was significant for independent variable level combinations $0 \%$ peat and $0 \%$ steer manure $0.06 \pm 0.01_{\mathrm{A}}^{*}, 2 \%$ peat and $0 \%$ steer manure $0.06 \pm 0.02 *, 3 \%$ peat and $0 \%$ steer manure $0.07 \pm 0.01_{\mathrm{A}}^{*}, 1 \%$ peat and $3 \%$ steer manure $0.09 \pm 0.01_{\mathrm{A}}^{*}$, $0 \%$ peat and $5 \%$ steer manure $0.09 \pm 0.01_{\mathrm{A}}^{*}$, and not significant for $0 \%$ peat and $4 \%$ steer manure; PRO was significant for: $0 \%$ peat and $0 \%$ steer manure $1.11 \pm 0.35^{*}, 3 \%$ peat and $0 \%$ steer manure $1.06 \pm 0.35_{\mathrm{A}}^{*}, 1 \%$ peat and $3 \%$ steer manure $1.33 \pm 0.35_{\mathrm{A}}^{*}, 0 \%$ peat and $5 \%$ steer manure $1.16 \pm 0.35_{\mathrm{A}}^{*}$, and not significant for both $2 \%$ peat and $0 \%$ steer manure, and $0 \%$ peat and $4 \%$ steer manure; TAU was significant for independent variable level combinations $0 \%$ peat and $0 \%$ steer manure 0.05 $\pm 0.011_{\mathrm{A}}^{*}, 2 \%$ peat and $0 \%$ steer manure $0.08 \pm 0.02{ }_{\mathrm{A}}^{*}, 1 \%$ peat and $3 \%$ steer manure $0.05 \pm 0.01_{\mathrm{A}}^{*}, 0 \%$ peat and $4 \%$ steer manure $0.08 \pm 0.02_{\mathrm{A}}^{*}$, and not significant for both $3 \%$ peat for $0 \%$ steer manure, and $0 \%$ peat for $5 \%$ steer manure.

\section{SI 3.6. Results in the Variety $x$ COA, Variety $x$ Peat, Variety $x$ Steer Manure, Variety $x$ COA and Structure $x$ COA ANOVAs and $L S$-Means with no Greenhouse Data for var. ' $T$ '}

There were no hypotheses for variety or COA. There were no significant results for the variety x COA (EXT Table 4) or variety $x$ peat (EXT Table 5) ANOVAs. ANOVAs for variety $x$ steer manure (EXT Table 6) both without and with the interaction term request were significant only for dispensable HLY and only for variety, with the exact same results both without and with the interaction term request, given previously in SI 2.11.

For these reasons, results were summarized in this one SI section for the variety x COA (EXT Table 14), variety x peat (EXT Table 15) and variety $\mathrm{x}$ steer manure (EXT Table 16) Tukey-adjusted LS-Means. There were several significant results for structure in the structure x COA ANOVAs (EXT Table 
7; see SI 2.12 and SI 3.2), as well as a single positive result for COA for CRDP in the same analyses, as COA was an independent variable. No significant results were computed in the Tukey-adjusted LS-Means for structure x COA (EXT Table 17, see SI 2.13).

Positive results for the indispensable amino acids and totals in the Tukey-adjusted LS Means analyses for variety x COA with no greenhouse data for var. ' $T$ ' (EXT Table 14) were: HLY significant for all variable level combinations which included var. ' $L$ ' control $0.15 \pm 0.02_{\mathrm{A}}^{*}$, var. ' $L$ ' $5 \%$ steer manure 0.12 $\pm 0.02_{\mathrm{A}}{ }^{*}$, var. ' $T$ ' $4 \%$ steer manure $0.13 \pm 0.03_{\mathrm{A}}{ }^{*}$, var. ' $L$ ' $1 \%$ peat and $3 \%$ steer manure $0.13 \pm 0.02_{\mathrm{A}}^{*}$, var. ' $T$ ' $2 \%$ peat $0.24 \pm$ $0.03_{\mathrm{A}}{ }^{*}$, and var. ' $L$ ' $3 \%$ peat $0.14 \pm 0.02_{\mathrm{A}}^{*}$; HPR significant for five of six variable level combinations which included var. ' $L$ ' control $0.06 \pm 0.01_{\mathrm{A}}^{*}$, var. ' $L$ ' $5 \%$ steer manure $0.09 \pm 0.01_{\mathrm{A}}^{*}$, var. ' $L$ ' $1 \%$ peat and $3 \%$ steer manure $0.09 \pm 0.01_{\mathrm{A}}{ }^{*}$, var. ' $T$ ' $2 \%$ peat $0.06 \pm 0.02_{\mathrm{A}}^{*}$, and var. ' $L$ ' $3 \%$ peat $0.07 \pm 0.01_{\mathrm{A}}{ }^{*}$, and not significant for var. ' $T$ ' $4 \%$ steer manure; and PRO significant for four of six variable level combinations which included var. ' $L$ ' control $1.11 \pm 0.35 *$, var. ' $L$ ' $5 \%$ steer manure $1.16 \pm 0.35$ *, var. ' $L$ ' $1 \%$ peat and $3 \%$ steer manure $1.33 \pm 0.35_{A}^{*}$, var. ' $L$ ' $3 \%$ peat $1.06 \pm 0.35_{\mathrm{A}}^{*}$, and not significant for var. ' $T$ ' $4 \%$ steer manure and var. ' $T$ ' $2 \%$ peat; TAU significant for four of six variable level combinations which included var. ' $L$ ' control $0.05 \pm$ $0.01_{\mathrm{A}}{ }^{*}$, var. ' $T$ ' $4 \%$ steer manure $0.08 \pm 0.02_{\mathrm{A}}{ }^{*}$, var. ' $L$ ' $1 \%$ peat and $3 \%$ steer manure $0.05 \pm 0.01_{\mathrm{A}}{ }^{*}$, and var. ' $T$ ' $2 \%$ peat 0.08 $\pm 0.02^{*}$ ', and not significant for var. ' $L$ ' $5 \%$ steer manure and var. ' $L$ ' $3 \%$ peat. Positive results for the indispensable amino acids and totals in the Tukey-adjusted LS Means analyses for variety $x$ peat with no greenhouse data for var. ' $T$ ' (EXT Table 15) were: indispensable THR significant only for var. ' $L$ ' $0 \%$ peat $0.66 \pm 0.24_{A^{*}}$, and not significant for var. ' $T$ ' $0 \%$ peat, var. ' $L$ ' $1 \%$ peat, var. ' $T$ ' $2 \%$ peat, and var. ' $L$ ' $3 \%$ peat; dispensable ALA significant only for var. ' $L$ ' $0 \%$ peat $0.83 \pm 0.29{ }_{\mathrm{A}}^{*}$, and not significant for var. ' $T$ ' $0 \%$ peat, var. ' $L$ ' $1 \%$ peat, var. ' $T$ ' $2 \%$ peat, and var. ' $L$ ' $3 \%$ peat; HLY significant for var. ' $L$ ' $0 \%$ peat $0.14 \pm 0.01_{\mathrm{A}}{ }^{*}$, var. ' $T$ ' $0 \%$ peat $0.13 \pm 0.03_{\mathrm{A}}{ }^{*}$, var. ' $L$ ' $1 \%$ peat $0.13 \pm 0.02_{\mathrm{A}}^{*}$, var. ' $L$ ' $1 \%$ peat $0.14 \pm 0.02_{\mathrm{A}}^{*}$; var. ' $T$ ' $2 \%$ peat $0.24 \pm 0.03^{*}$, var. ' $L$ ' $3 \%$ peat $0.14 \pm 0.02_{\mathrm{A}}^{*}$; HPR significant for var. ' $L$ ' $0 \%$ peat $0.07 \pm 0.01_{\mathrm{A}}^{*}$, var. ' $L$ ' $1 \%$ peat $0.09 \pm$ $0.01_{\mathrm{A}}^{*}$, var. ' $T$ ' $2 \%$ peat $0.06 \pm 0.02_{\mathrm{A}}^{*}$; ; var. ' $L$ ' $3 \%$ peat $0.07 \pm$ $0.01_{\mathrm{A}}{ }^{*}$, and not significant for var. ' $T$ ' $0 \%$ peat $0.04 \pm 0.02_{\mathrm{A}}^{*}$; PRO significant for var. ' $L$ ' $0 \%$ peat $1.14 \pm 0.22{ }^{*}$, var. ' $L$ ' $1 \%$ peat $1.33 \pm 0.32{ }^{*}$, var. ' $T$ ' $2 \%$ peat $1.33 \pm 0.45_{\mathrm{A}}{ }^{*}$, var. ' $L$ ' $3 \%$ peat $1.06 \pm 0.32{ }^{*}$, and not significant for var. ' $T$ ' $0 \%$ peat 0.91 $\pm 0.45_{A}$; SER significant only for var. ' $L$ ' $0 \%$ peat $0.60 \pm 0.22_{\mathrm{A}}^{*}$, and not significant for var. ' $T$ ' $0 \%$ peat, var. ' $L$ ' $1 \%$ peat, var. ' $T$ ' $2 \%$ peat, and var. ' $L$ ' $3 \%$ peat; TAU significant for all variable level combinations which included var. ' $L$ ' $0 \%$ peat $0.04 \pm$ $0.01_{\mathrm{A}}{ }^{*}$, var. ' $T$ ' $0 \%$ peat $0.08 \pm 0.02_{\mathrm{A}}^{*}$, var. ' $L$ ' $1 \%$ peat $0.05 \pm$ $0.01_{\mathrm{A}}^{*}$, var. ' $T$ ' $2 \%$ peat $0.08 \pm 0.02_{\mathrm{A}}^{*}$, and not significant var. ' $L$ ' $3 \%$ peat; and CRDP significant only for var. ' $L$ ' $0 \%$ peat $19.09 \pm 6.49{ }_{\mathrm{A}}^{*}$, and not significant for var. ' $T$ ' $0 \%$ peat, var. ' $L$ ' $1 \%$ peat, var. ' $T$ ' $2 \%$ peat, and var. ' $L$ ' $3 \%$ peat.

Positive results for the indispensable amino acids and totals in the Tukey-adjusted LS Means analyses for variety x steer manure with no greenhouse data for var. ' $T$ ' (EXT Table 16) were: indispensable LYS significant for all variable level combinations which included var. ' $L$ ' $0 \%$ steer manure (see Table 4), and was not significant for var. ' $T$ ' $0 \%$ steer manure, var. ' $L$ ' $3 \%$ steer manure, var. ' $T$ ' $4 \%$ steer manure, and var. ' $L$ ' $5 \%$ steer manure; THR significant only for var. ' $L$ ' $0 \%$ steer manure 0.65 $\pm 0.24_{\mathrm{A}}{ }^{*}$, and was not significant for var. ' $T$ ' $0 \%$ steer manure, var. ' $L$ ' $3 \%$ steer manure, var. ' $T$ ' $4 \%$ steer manure, and var. ' $L$ ' $5 \%$ steer manure; dispensable ALA significant only for var. ' $L$ ' $0 \%$ steer manure $0.84 \pm 0.29{ }^{*}$, and was not significant for var. ' $T$ ' $0 \%$ steer manure, var. ' $L$ ' $3 \%$ steer manure, var. ' $T$ ' $4 \%$ steer manure, and var. ' $L$ ' $5 \%$ steer manure; HLY highly significant for var. ' $L$ ' $0 \%$ steer manure $0.15 \pm 0.01_{\mathrm{A}}^{* *}$, and significant for var. ' $T$ ' $0 \%$ steer manure $0.24 \pm 0.03_{\mathrm{A}}{ }^{*}$, var. ' $L$ ' $3 \%$ steer manure $0.13 \pm 0.02_{\mathrm{A}}{ }^{*}$, var. ' $T$ ' $4 \%$ steer manure $0.13 \pm 0.03_{\mathrm{A}}{ }^{*}$, var. ' $L$ ' $5 \%$ steer manure $0.12 \pm 0.02_{\mathrm{A}}^{*}$; HPR significant for var. ' $L$ ' $0 \%$ steer manure $0.06 \pm 0.01_{A}^{*}$, var. ' $T$ ' $0 \%$ steer manure $0.06 \pm 0.02_{\mathrm{A}}^{*}$, var. ' $L$ ' $3 \%$ steer manure $0.09 \pm 0.01_{\mathrm{A}}^{*}$, var. ' $L$ ' $5 \%$ steer manure $0.09 \pm 0.01_{\mathrm{A}}^{*}$; and not significant for var. ' $T$ ' $4 \%$ steer manure; PRO significant for var. ' $L$ ' $0 \%$ steer manure $1.08 \pm 0.22_{\mathrm{A}}{ }^{*}$, var. ' $T$ ' $0 \%$ steer manure $1.33 \pm 0.45_{\mathrm{A}}{ }^{*}$, var. ' $L$ ' $3 \%$ steer manure $1.33 \pm 0.32_{\mathrm{A}}^{*}$, var. ' $T$ ' $4 \%$ steer manure 0.91 $\pm 0.45_{\mathrm{A}}^{*}$, and var. ' $L$ ' $5 \%$ steer manure $1.16 \pm 0.32_{\mathrm{A}}^{*}$; SER significant only for var. ' $L$ ' $0 \%$ steer manure $0.59 \pm 0.22_{\mathrm{A}}{ }^{*}$, and not significant for var. ' $T$ ' $0 \%$ steer manure, var. ' $L$ ' $3 \%$ steer manure, var. ' $T$ ' $4 \%$ steer manure, and var. ' $L$ ' $5 \%$ steer manure; TAU significant for var. ' $L$ ' $0 \%$ steer manure $0.04 \pm 0.01_{A}^{*}$, var. ' $T$ ' $0 \%$ steer manure $0.08 \pm 0.02_{\mathrm{A}}^{*}$, var. ' $L$ ' $3 \%$ steer manure $0.05 \pm 0.02^{*}$ ', and not significant for var. ' $T$ ' $4 \%$ steer manure and var. ' $L$ ' $5 \%$ steer manure; and CRDP significant only for var. ' $L$ ' $0 \%$ steer manure $18.63 \pm 6.48_{A}^{*}$, and not significant for var. ' $T$ ' $0 \%$ steer manure, var. ' $L$ ' $3 \%$ steer manure, var. ' $T$ ' $4 \%$ steer manure, and var. ' $L$ ' $5 \%$ steer manure.

\section{SI 3.7. Comparison of the Tukey-adjusted LS-Means and ANOVA Results for the Peat $x$ Steer Manure Analyses with no Greenhouse Data for var. ' $T$ '}

There were no positive results in the ANOVAs for the independent variables of peat $\mathrm{x}$ steer manure with no greenhouse data for var. ' $T$ ' (EXT Table 10). Therefore, results for the peat $\mathrm{x}$ steer manure Tukey-adjusted LS-Means (EXT Table 20) were considered alone.

\section{SI 3.8. Tukey-adjusted LS-Means Tables Named though not Presented in the Supporting Information}

Positive results were not presented in full from the structure $\mathrm{x}$ variety Tukey-adjusted LS-Means analyses that included leaf, however, no greenhouse stem data for var. ' $T$ ' (EXT Table 12) and also for the LS-Means analyses that did not include any greenhouse data for var. ' $T$ ' (EXT Table 13). No positive results were generated in the Tukey-adjusted LS-Means analyses of structure $\mathrm{x}$ combined organic amendments (EXT Table 17; see SI 3.6). This was despite significance for structure in the structure x COA ANOVAs (EXT Table 7), for all ten indispensable amino acids, CRDP, TOTP and for nine of the 13 dispensable amino acids assayed. Distribution of negative results and un- 
computed results for EXT Tables 12, 13 and 17 have been presented previously in Appendix C-7 of Kritzer Van Zant (2016a). LS-Means EXT Tables 12, 13 and 17 correlated consecutively with EXT ANOVA Tables 2, 3 and 7. As only results from ANOVA EXT Table 1 of ANOVA EXT Tables 1-3 were presented in the SI, the lack of consideration of results from EXT Tables 2 and 3 for comparison to EXT Tables 12 and 13 had no meaning here, though the negative results from all extended tables are available for consideration in Kritzer Van Zant (2016a). EXT Tables 1 and 11 were also for the pair-wise comparison of structure $\mathrm{x}$ variety, and both had positive results that were presented below and considered relative to each other. The ANOVA for structure x combined organic amendments (EXT Table 7) had positive results that were considered alone, as they could not be compared with positive Tukey-adjusted LS-Means results for the same pair of variables, since they were lacking.

\section{SI 4. Summaries of Independent Variables}

\section{SI 4.1. Independent Variable Structure}

The structure hypothesis for var. ' $L$ ', was addressed for the independent variable structure, using the structure x peat (EXT Tables 6, 16), structure x steer manure (EXT Tables 9, 19) and structure x COA (EXT Tables 7, 17) analyses, as appropriate in the body of the paper. In addition, the structure $\mathrm{x}$ variety (EXT Tables 1, 11) ANOVA and LS-means analyses were examined below. Discussion for structure is organized around the high return of significant results in the structure $\mathrm{x}$ variety ANOVAs, even though all pairs of independent variables including variety, were considered separately from the hypotheses. Structure had the most significance of any independent variable. The hypothesis for structure is repeated here for convenience.

$\mathrm{H}_{0}=$ There will not be a significant difference in quantity for each amino acid, between above and below ground plant parts, and $\mathrm{H}_{1}=$ There will be a significant difference in quantity for each amino acid, between above and below ground plant parts.

\section{SI 4.1.1. ANOVA Analyses for the Independent Variable Structure}

For the independent variable structure, in the ANOVAs for structure $\mathrm{x}$ variety (EXT Table 1) without and with the interaction term request, all ten indispensable amino acids, ARG, HIS, ISO, LEU, LYS, MET, PHE, THR, and VAL, and both CRDP and TOTP were consistently highly significant in full agreement in the structure hypothesis with $\mathrm{H}_{1}$.

For the independent variable structure, in the ANOVAs for structure $x$ COA (EXT Table 7), without the interaction term request, indispensable ARG, HIS, ISO, LEU, LYS, MET, PHE, THR, VAL, and both CRDP and TOTP, were highly significant while indispensable TRP was significant, in agreement in the structure hypothesis with $\mathrm{H}_{1}$.

For the independent variable structure, in the ANOVAs for structure $\mathrm{x}$ COA (EXT Table 7), with the interaction term request, no results were generated for any dependent variable.

For the independent variable structure, in the ANOVAs for structure $\mathrm{x}$ peat (EXT Table 8), without and with the interaction term request, all ten indispensable amino acids and both CRDP and TOTP, were highly significant in full agreement for the structure hypothesis with $\mathrm{H}_{1}$.

For the independent variable structure, in the ANOVAs for structure $\mathrm{x}$ steer manure (EXT Table 9), supporting $\mathrm{H}_{1}$ in the structure hypothesis were: indispensable ARG, ISO, LEU, MET, PHE, THR and VAL, which were highly significant without and with the interaction term request; and indispensable HIS, LYS and TRP, and both CRDP and TOTP, which were highly significant without the interaction term request and significant with the interaction term request.

In summary, for the structure hypothesis, most indispensable amino acids fully supported $\mathrm{H}_{1}$ meaning that there was a distinction in the amounts of most amino acids and CRDP and TOTP between above and below ground plant parts. The only exceptions were dispensable HLY, HPR and TAU which supported $\mathrm{H}_{0}$, indicating there was no distinction in the amounts of these amino acids between above and below ground plant parts.

\section{SI 4.1.2. LS-Means Analyses for the Independent Variable Structure}

In the structure $\mathrm{x}$ variety LS-Means analyses with all greenhouse data included (EXT Table 11), nearly every indispensable amino acid and both categories were highly significant for all level combinations. The structure $\mathrm{x}$ variety LS-Means analyses supported $\mathrm{H}_{1}$ for the structure hypothesis and indicated that variety may have also had meaning for differences in the amino acid profiles for M. expansa.

In the structure $\mathrm{x}$ variety LS-Means analyses with all greenhouse data included (EXT Table 11), most dispensable amino acids were highly significant for all level combinations though ALA and GLU dropped to significant for var. ' $T$ ' stem, which was still in support of $\mathrm{H}_{1}$ for the structure hypothesis and indicated that variety may also have had meaning for differences in the amino acid profiles for $M$. expansa.

In the structure $\mathrm{x}$ variety LS-Means analyses with all greenhouse data included (EXT Table 11), the highest amounts of all ten indispensable amino acids were found in leaf of var. ' $L$ ', then leaf of var. ' $T$ ', which was in support of $H_{1}$ in the structure hypothesis.

In the structure $\mathrm{x}$ COA LS-Means analyses with no greenhouse data included (EXT Table 17; see SI 3.6), none of the level combinations had significant differences so they were not detailed in discussion. This lack of significance in the structure $x$ COA LS-Means may have supported $\mathrm{H}_{0}$ in the structure hypothesis, or may just have been due to too many imbalances in the data for these analyses to resolve that combination of independent variables.

For the independent variables structure and peat, in the structure $x$ peat LS-Means analyses with no greenhouse data included (EXT Table 18; see results in SI 3.3 and Tables 2, 4 and 6), $H_{1}$ was supported in both the structure and peat hypotheses by: indispensable MET which was the only amino acid highly significant for all levels of peat for both leaf and root; most indispensable and dispensable amino acids, and CRDP, as they 
were highly significant for all levels of peat for leaf, and significant for all levels of peat for root; and TOTP which was highly significant for all levels of peat for leaf and for the control for root, and significant for the other levels of peat.

In the structure $\mathrm{x}$ peat LS-Means analyses with no greenhouse data included (EXT Table 18; see results in SI 3.3 and Tables 2, 4 and 6), indispensable amino acids for the most part, and CRDP and TOTP, were present in higher amounts in leaf over root for all levels of peat, which gave support to $\mathrm{H}_{1}$ for the structure hypothesis.

In the structure $\mathrm{x}$ steer manure LS-Means analyses with no greenhouse data included (EXT Table 19; see results in SI 3.4 and Tables 2, 4 and 6), for both structure and steer manure in support, of $\mathrm{H}_{1}$, respectively for the structure and steer manure hypothesis: most indispensable and most dispensable amino acids were highly significant for leaf and significant for structure for all levels of steer manure; indispensable MET and TRP were only highly significant for leaf for the control for steer manure, and were significant for all other level combinations for leaf and all level combinations for root; TOTP was highly significant for the control for leaf and significant for all other levels of steer manure for leaf and for all levels of steer manure for root; and CRDP was significant for all levels of steer manure for leaf and root. In the structure $\mathrm{x}$ steer manure LSMeans analyses with no greenhouse data included (EXT Table 19), all indispensable and most dispensable amino acids were present in consistently higher amounts in leaf over root, which gave support to $\mathrm{H}_{1}$ for the structure hypothesis. For the steer manure hypotheses, these same LS-Means results were in contradiction to the ANOVA results, which consistently supported $\mathrm{H}_{0}$ for the steer manure hypotheses, though these analyses were not applied to that hypothesis in the body of the paper.

\section{SI 4.2. Independent Variable Variety}

For the independent variable variety, examination of ANOVAs could only be made for non-statistical obvious patterns in the data. The two varieties were only grown in the same year once, and with similar yet different amounts of soil amendments. Variety was included in pair-wise comparisons in the structure $\mathrm{x}$ variety (EXT Tables 1,11$)$, variety x COA (EXT Tables 4,14$)$, variety $x$ peat (EXT Tables 5,15 ) and variety $\mathrm{x}$ steer manure (EXT Tables 6, 16) ANOVAs (EXT Tables 1, 4, 5,6 ) and LS-Means (EXT Tables 11, 14, 15, 16) analyses. No hypothesis was given for variety, so it was only examined for obvious patterns of significance.

\section{SI 4.2.1. ANOVA Analyses for the Independent Variable Va- riety}

For the independent variable variety, in the structure $\mathrm{x}$ variety ANOVAs (EXT Table 1) with the interaction term request, indispensable PHE was highly significant and indispensable ARG, HIS, ISO, LEU, LYS, MET, THR, TRP and VAL, and TOTP, were significant.

For the independent variable variety, in the structure $\mathrm{x}$ variety ANOVAs (EXT Table 1) without the interaction term re- quest, indispensable ARG, HIS, ISO, LEU, LYS, MET, PHE, THR, TRP and VAL, and both CRDP and TOTP, and with the interaction term request, CRDP, were not significant.

Variety x COA ANOVAs (EXT Tables 4, 14) were too imbalanced to produce any significant results for variety, also for the interaction between variety and COA for any amino acid or category. Therefore, the structure x COA ANOVAs were not analyzed further.

For the independent variable variety, in the variety $\mathrm{x}$ peat ANOVAs (EXT Table 5) without and with the interaction term request, all ten indispensable amino acids, and both CRDP and TOTP, were not significant. Though this seemed to have fully supported $\mathrm{H}_{0}$ in both the structure and peat hypotheses, variety had no statistical significance for either.

For the independent variable variety, in the variety $\mathrm{x}$ steer manure ANOVAs (EXT Table 6) without and with the interaction term request, all ten indispensable amino acids were not significant.

In summary, though there was no hypothesis considered for variety, all indispensable amino acids in the structure $\mathrm{x}$ variety ANOVAs were at least significant with the interaction term request, and so were most of the dispensable amino acids. However, the opposite was true without the interaction term request and in the variety $\mathrm{x}$ peat and variety $\mathrm{x}$ steer manure ANOVAs. It may be possible to distinguish varieties of $M$. expansa from each other with amino acid profiles, though only after using meaningful calculations to analyze sufficient data for that purpose.

\section{SI 4.2.2. LS-Means analyses for the Independent Variable Va- riety}

Structure x variety Tukey adjusted LS-Means (EXT Table 11) analyses were already examined above under LS-Means for structure.

Variety x COA LS-Means (EXT Table 14; see SI 3.6) analyses were not significant for any indispensable amino acid, and not for CRDP or TOTP.

Variety x peat adjusted LS-Means (EXT Table 15; see SI 3.6 and Tables 2 and 4) analyses had significance only for var. ' $L$ ' for the control for peat for indispensable LYS and THR, and for CRDP.

Variety x peat adjusted LS-Means (EXT Table 15) analyses had no significance for other indispensable amino acids, nor for remaining level combinations for the previously mentioned amino acids, and CRDP, and no significance for TOTP.

Variety x steer manure Tukey-adjusted LS-Means (EXT Table 16; see SI 3.6) analyses for var. ' $L$ ' for the control for steer manure were highly significant for dispensable HLY and significant for indispensable LYS and THR, and for CRDP.

Variety x steer manure LS-Means (EXT Table 16) analyses for var. ' $L$ ' for all other amino acids and level combinations were not significant for any other indispensable amino acids and not for TOTP. 


\section{SI 4.3. Independent Variable Peat}

Independent variable peat was addressed for the peat hypothesis in the variety $\mathrm{x}$ peat (EXT Tables 5,15$)$, structure $\mathrm{x}$ peat $($ EXT Tables 8,18$)$ and peat $\mathrm{x}$ steer manure (EXT Tables $10,20)$ analyses.

Peat $\mathrm{x}$ steer manure analyses were added after the other pairwise variables were analyzed, so do not apply directly to any of the original hypotheses. The peat hypothesis is repeated here for convenience.

$\mathrm{H}_{0}=$ Amount of peat added at the time of plot construction, has no effect on the amount of amino acid produced, considered individually, in roots and separately in shoots, and $\mathrm{H}_{1}=$ Amount of peat added at the time of plot construction has an effect on the amount of amino acid produced, considered individually, in roots and separately in shoots.

\section{SI 4.3.1. ANOVA Analyses for the Independent Variable Peat}

For the independent variable peat, in the variety $\mathrm{x}$ peat ANOVAs (EXT Table 5) without and with the interaction term request, all ten indispensable amino acids, and both CRDP and TOTP, were not significant in full support of $\mathrm{H}_{0}$ for the peat hypothesis.

For the independent variable peat, in the variety $\mathrm{x}$ peat ANOVAs (EXT Table 5) without and with the interaction term request, all amino acids with significant results were computed to be fully in support of $\mathrm{H}_{0}$ for the peat hypothesis.

For the independent variable peat, in the structure $\mathrm{x}$ peat (EXT Table 8) ANOVAs, which were in support of $\mathrm{H}_{1}$ for the peat hypothesis were: significant without and with the interaction term request- indispensable HIS and GLU, and TOTP; without the interaction term request- significant CRDP; and with the interaction term request- significant indispensable MET and CYS.

For the independent variable peat, in the structure $\mathrm{x}$ peat (EXT Table 8) ANOVAs, lacking significance in support of $\mathrm{H}_{0}$ for the peat hypothesis were: without and with the interaction term request- indispensable ARG, ISO, LEU, LYS, PHE, THR, TRP and VAL; without the interaction term request- indispensable MET and dispensable CYS; and with the interaction term request- CRDP.

For the independent variable peat, in the peat $\mathrm{x}$ steer manure (EXT Table 10) ANOVAs, without and with the interaction term request, there was no significance for any of the ten indispensable amino acids, and both CRDP and TOTP, which fully supported $\mathrm{H}_{0}$ for the peat hypothesis.

\section{SI 4.3.2. LS-Means Analyses for the Independent Variable Peat}

Independent variable peat was addressed for the peat hypothesis in the variety $\mathrm{x}$ peat (EXT Table 15; see SI 3.6 and Tables 2 and 4), structure $x$ peat (EXT Table 18), structure $x$ steer manure (EXT Table 19) and peat $\mathrm{x}$ steer manure (EXT Table 20) Tukey-adjusted LS-Means analyses.

Independent variable peat was addressed for the peat hy- pothesis in the variety x peat (EXT Table 15), LS-Means analyses, in the LS-Means analyses section for variety, above.

Independent variable peat was addressed for the peat hypothesis in the structure x peat (EXT Table 18) LS-Means analyses, in the LS-Means analyses section for structure, above. In structure $x$ peat (EXT Table 18) LS-Means analyses, most indispensable and dispensable amino acids, and CRDP, supported $\mathrm{H}_{1}$ in the peat hypothesis, which indicated that there was an effect of peat on amino acid production.

Independent variable peat in the peat $\mathrm{x}$ steer manure (EXT Table 20) LS-Means analyses, was not significant for all level combinations for all ten of the indispensable amino acids, most dispensable amino acids, and was not significant for either CRDP or TOTP. Therefore, in the peat $\mathrm{x}$ steer manure LSMeans analyses most dependent variables supported $\mathrm{H}_{0}$ in both the peat and steer manure hypotheses.

\section{SI 4.4. Independent Variable Steer Manure}

Independent variable steer manure was addressed for the steer manure hypotheses, in the variety x steer manure (EXT Tables 6,16), structure x steer manure (EXT Tables 9, 19) and peat $\mathrm{x}$ steer manure (EXT Tables 10,20) analyses. As the peat $\mathrm{x}$ steer manure analyses were added after the other pair-wise variables were analyzed, peat $\mathrm{x}$ steer manure did not apply directly to any of the original hypotheses. Peat $x$ steer manure could only be discussed without statistical meaning. The steer manure hypothesis is repeated here for convenience.

$\mathrm{H}_{0}=$ Amount of steer manure added at the time of plot construction has no effect on the amount of amino acid produced, considered individually, in roots and separately in shoots, and $\mathrm{H}_{1}=$ Amount of steer manure added at the time of plot construction has an effect on the amount of amino acid produced, considered individually, in roots and separately in shoots. This hypothesis was addressed for the independent variable steer manure, in the structure x steer manure ANOVAs (EXT Table 9) and LS-Means (EXT Table 19; see results in SI 3.4 and Tables 2, 4 and 6) analyses.

\section{SI 4.4.1. ANOVA Analyses for the Independent Variable Steer Manure}

For the independent variable steer manure, in the variety $\mathrm{x}$ steer manure (EXT Table 6) ANOVAs, without and with the interaction term request, all ten indispensable amino acids, as well as both CRDP and TOTP, were not significant which fully supported $\mathrm{H}_{0}$ in the steer manure hypothesis.

For the independent variable steer manure, in the structure $x$ steer manure (EXT Table 9) ANOVAs, without and with the interaction term request, all ten indispensable amino acids, and CRDP and TOTP, were not significant which fully supported $\mathrm{H}_{0}$ in the steer manure hypothesis.

For the independent variable steer manure, in the peat $\mathrm{x}$ steer manure (EXT Table 10) ANOVAs, without and with the interaction term request, all ten indispensable amino acids, and both CRDP and TOTP, were not significant, which fully supported $\mathrm{H}_{0}$ in the steer manure hypothesis. 
SI 4.4.2. LS-Means Analyses for the Independent Variable Steer Manure

Independent variable steer manure was addressed in the variety x steer manure (EXT Table 16; see SI 3.6 and Tables 2 and 4) Tukey-adjusted LS-Means analyses, above, under the heading, SI 4.2.2. LS-Means for the Independent Variable Variety.

Independent variable steer manure was also addressed in the structure x steer manure (EXT Table 19; see results in SI 3.4 and Tables 2, 4 and 6) Tukey-adjusted LS-Means analyses above, under the heading, SI 4.1.2. LS-Means for the Independent Variable Structure.

Independent variable steer manure was addressed in the peat $\mathrm{x}$ steer manure (EXT Table 20) Tukey-adjusted LS-means under the heading SI 4.3.2. LS-Means for the Independent Variable Peat.

\section{SI 4.5. Independent Variable COA}

Both the peat and steer manure hypotheses partially examined the independent variable COA. COA was utilized in the variety x COA (EXT Tables 4, 14) and structure x COA (EXT Tables 7, 17), analyses. In addition, both peat and steer manure were considered in the peat $\mathrm{x}$ steer manure (EXT Tables 10, $20)$ analyses. These analyses were considered above under the ANOVA and LS-Means heading for the individual independent variables, so will not be repeated here. The meaning of COA had to be weighed against the totality of the imbalances in the data, as most of them came into play in the COA analyses.

It could be said that in the ANOVAs, most results concerned with peat vs. steer manure showed that there was a mild influence on the amino acid profiles for $M$. expansa from peat, which will require sufficient data and proper mathematical consideration to find if the effect of peat is consistent, if possible. Also, the effect of steer manure was mostly non-existent. Yet, especially from the LS-Means results, it appeared that either soil amendment may have a limited benefit. We speculated that this was due to soil amendments having had the effect of increasing water retention in the root zone, which $M$. expansa reacts poorly to, and that it was less likely to have been from the presence of the amendments as nutrient sources. As the amendments had been added to the plots years before the work on $M$. expansa commenced, it may be that this effect was magnified by additions of equal amounts of mushroom composted steer manure, equally aged for each year, into the hole dug for every plant. This amendment was only added at the time of planting. The increased age of the steer manure may have also affected the outcome between years and therefore to some extent between varieties.

\section{SI 4.6. Interactions in the ANOVAs}

As it was necessary to separate the independent variables for purposes of discussing the data for $M$. expansa in a meaningful manner, it was also necessary to separate the meaning of interactions in all of the ANOVA analyses. This was done separately for each ANOVA analyses and presented in the or- der of the ANOVA tables though there was some discussion of interactions above.

Interactions for structure and variety, in the structure $\mathrm{x}$ variety ANOVAs (EXT Table 1), for indispensable ARG, PHE, TRP and VAL, and dispensable ASP, GLU, GLY and TYR, and TOTP were highly significant, while indispensable HIS, LEU, LYS, MET and THR, and CRDP, were significant.

Interactions were not computed for significance for any dependent variable in the variety x COA (EXT Table 4), variety x peat (EXT Table 5), variety x steer manure (EXT Table 6), structure $\mathrm{x}$ COA (EXT Table 7) and peat $\mathrm{x}$ steer manure (EXT Table 10) ANOVAs, which indicated that imbalances in the data were too great for those analyses to compute the interaction results.

Interactions for structure and variety, in the structure $\mathrm{x}$ variety ANOVAs (EXT Table 1), for all ten indispensable amino acids, and both CRDP and TOTP were at least significant, which was in keeping with the large amounts of significance for both independent variables.

Interactions for structure and peat, in the structure $\mathrm{x}$ peat ANOVAs (EXT Table 8), were only significant for indispensable MET and dispensable CYS and TYR, and were not significant for any other indispensable or dispensable amino acid, and not for either CRDP or TOTP, and were not computed for dispensable LAN and ORN. As peat had already been shown to probably have had a slight effect on amino acid production, it may be that structure was another contributor to the uncertainty of the effect of peat, and that peat may have influenced the balance of amino acids in the upper and lower parts of $M$. expansa grown in southern Illinois.

Interactions for structure and steer manure, in the structure $\mathrm{x}$ steer manure ANOVAs (EXT Table 9), were not significant for all dependent variables. This was a consistent outcome. Taken as a whole, results of these interactions show that structure and variety affect each other, and to a more limited extent so do structure and peat, while structure and steer manure have no effect on each other. It was not possible to determine whether there were interaction effects for any of the other independent variable combinations.

\section{SI 5. Summary of Additional Considerations for Resolution of Hypotheses}

For the structure hypotheses, in the ANOVA analyses for structure $\mathrm{x}$ variety including all positive data reported (EXT Table 1), structure x COA (EXT Table 7), structure x peat (EXT Table 8) and structure x steer manure (EXT Table 9), without and with the interaction term request, all ten indispensable amino acids, and both CRDP and TOTP, supported $\mathrm{H}_{1}$, further supporting that structure had an effect on amino acid production. Most amino acids also had good support for $\mathrm{H}_{1}$ for the structure hypothesis in the Tukey-adjusted LS-Means results.

Variety gave mixed results and was without statistical meaning for any of the given hypotheses. The presence or absence of an interaction term request caused results to change from supporting an effect from variety to not supporting that effect. Larger sample sizes and improvements in the balance of raw 
data may give clearer results. In the LS-Means for variety results were mixed, depending on which other independent variable was paired with variety. In the LS-Means for variety x peat (EXT Table 15; see SI 3.6 and Tables 2 and 4), indispensable LYS and THR, and CRDP, were the only significant dependent variables, and the only dependent variables to have had any significance for the control.

Results for peat were contradictory among pairs of independent variables in the ANOVAs, for the same dependent variables. In the structure x peat LS-Means (EXT Table 18; see SI 3.3 and Tables 2, 4 and 6), all indispensable amino acids, and both CRDP and TOTP, supported $\mathrm{H}_{1}$ for the peat hypothesis. In the variety $\mathrm{x}$ peat ANOVAs (EXT Table 5), indispensable amino acids were all not significant, which fully supported $\mathrm{H}_{0}$ for the peat hypothesis, and indicated there was no effect of peat on amino acid production. However, analyses with variety as an independent variable were not statistically meaningful relative to the hypotheses. In the variety $x$ peat LS-Means (EXT Table 15; see SI 3.6 and Tables 2 and 4) only indispensable LYS and THR, along with CRDP, appeared to have supported $\mathrm{H}_{1}$ for the peat hypothesis, as they were all significant. In the variety x peat LS-Means analyses (EXT Table 15) once again it appeared that peat did not have a significant effect on amino acid production for most amino acids and TOTP. Peat $\mathrm{x}$ steer manure ANOVAs (EXT Table 10) and LS-Means (EXT Table 20) were an afterthought, which did not apply to either the peat or steer manure hypotheses. Even so, both the ANOVAs (EXT Table 10) and LS-Means (EXT Table 20) for peat x steer manure seemed to have given full support to a lack of effect by peat.

For steer manure in the variety $\mathrm{x}$ steer manure ANOVAs (EXT Table 6) all independent variables lacked significance, which fully supported $\mathrm{H}_{0}$ for the steer manure hypothesis, and indicated that there was no effect of steer manure. For steer manure in the variety $\mathrm{x}$ steer manure LS-Means analyses (EXT Table 16; see SI 3.6 and Tables 2 and 4), indispensable LYS and THR, and CRDP, had significance though only for the control for var. ' $L$ '. For steer manure in the variety $\mathrm{x}$ steer manure LSMeans analyses (EXT Table 16), eight of the ten indispensable amino acids and TOTP lacked significance for all level combinations.

For steer manure in the structure $\mathrm{x}$ steer manure ANOVAs (EXT Table 9), full support by all independent variables was for $\mathrm{H}_{0}$ in the steer manure hypothesis, indicating there was no effect of steer manure on amino acid production. However, for the structure $\mathrm{x}$ steer manure LS-Means analyses (EXT Table 19; see results in SI 3.4 and Tables 2, 4 and 6) overwhelming support was for $\mathrm{H}_{1}$ in the steer manure hypothesis, indicating that there was an effect of steer manure on amino acid production in M. expansa.

Peat $\mathrm{x}$ steer manure ANOVAs (EXT Table 10) and LSMeans (EXT Table 20) were not applicable directly to the steer manure hypothesis because they were added as an afterthought. For steer manure in the peat $\mathrm{x}$ steer manure ANOVAs (EXT Table 10), all ten indispensable amino acids, and both CRDP and TOTP, supported $\mathrm{H}_{0}$ in the steer manure hypothesis, which indicated a lack of effect from steer manure on amino acid pro- duction.

For steer manure in the peat $\mathrm{x}$ steer manure LS-Means analyses (EXT Table 20), all ten indispensable amino acids, as well as both CRDP and TOTP, were not significant for all level combinations, which would have also supported a lack of effect by steer manure on amino acid production.

There was no hypothesis for COA prior to running the COA analyses. In addition, these analyses included plots with both steer manure and peat coded separately for each amendment. Coding the same plot twice while disregarded the effect of the other amendment each time, overemphasized the importance of each amendment as it was being coded. Perhaps these canceled each other out. However, this may also have compounded their individual impact. For COA in the variety x COA ANOVAs (EXT Table 4), all ten indispensable amino acids, and both CRDP and TOTP, were not significant. For COA in the variety x COA LS-Means analyses (EXT Table 14; see SI 3.6), all ten indispensable amino acids, and neither CRDP or TOTP had any amount of significance for any level combination, indicating a lack of effect from peat or steer manure.

For COA in the structure x COAANOVAs (EXT Table 7), all ten indispensable amino acids and TOTP, were not significant without the interaction term request, and with the interaction term request no significant results were computed. For COA in the structure x COA ANOVAs (EXT Table 7), only CRDP was significant and only without the interaction term request, and with the interaction term request no results that were computed had significance. COA in the structure x COA LS-Means analyses (EXT Table 17; see SI 3.6) had no significance for any independent variable.

Results of the variety x COA (EXT Tables 4,14$)$ and structure x COA (EXT Tables 7, 17) ANOVAs (EXT Tables 4, 7) and LS-Means analyses (EXT Tables 14, 17; see SI 3.6) seemed to have supported that neither peat nor steer manure had an effect on the production of most individual amino acids. This contrasted with limited support for an effect by peat, and less by steer manure, for most dependent variables, when each of these independent variables was considered alone. There were also conflicting results without the interaction term request, for CRDP for COA, which had no result with the interaction term request.

It seemed that there was a real effect of peat for the peat hypothesis, and there may also have been a slight effect of steer manure for the steer manure hypothesis. However, the individual effects of peat and steer manure were vague and hard to pin down with the data available for these analyses. It may be that the time span since the plots were constructed and/or imbalances in the data contributed to conflicting results for the effects of peat and steer manure on amino acid production. It was also possible that peat and/or steer manure had an effect on percentages of amino acids and their total production by $M$. expansa. It may be that any organic soil amendment that contributes nutrients can assist or limit the growth of M. expansa. A little was helpful. However, too much causes problems for the plant. It may be that the high amount of water sensitivity observed for M. expansa was a greater factor for the effect of both peat and steer manure than any contribution either may 
make as a source of nutrients. These results also seem to point to a low need for fertilizer for M. expansa.

\section{SI 6. Other Considerations}

High amounts of significance for structure indicated that all ten indispensable amino acids, and both CRDP and TOTP, were present in higher amounts in leaf over root. Though this is typical for most plants, it was less certain for M. expansa as it produces enlarged stem as well as enlarged root. However, it was also shown that the single sample of enlarged stem from variety ' $T$ ' had an amino acid profile more similar to those of root, than to those of leaf samples, even if leaf samples contained un-enlarged stem. This was true for var. ' $T$ ' enlarged stem compared with roots and shoots of either variety for most amino acids.

In spite of marked differences in quantity, it appears that the crop produced and/or stored a very similar quality of protein both above and below ground. M. expansa produced a good representation of dispensable as well as indispensable amino acids. The presence of the dispensable amino acids allows consumers of this crop to utilize more of the indispensable amino acids as they are, without having to convert them to dispensable amino acids, to make protein.

There were considerable and varied amounts of significance in four of the sets of analyses, all addressing the independent variable structure. However, some pairs of independent variables had little in common for patterns of significance without and with the interaction term request, and significance in the LS-Means analyses often contradicted one or both ANOVAs for the same pair of independent variables. In addition, the LSMeans analyses mostly showed little meaning for the amounts of significance for increasing or decreasing increments of soil amendments. The greatest differences were between the controls and other treatments for field grown var. ' $L$ '. For every independent variable in every ANOVA, there were differences in degrees of significance and exceptions to the general pattern of significance for different dependent variables. All ten indispensable amino acids had at least significant results for structure in the ANOVA analyses, as did CRDP and TOTP.

Only dispensable TAU was present in higher amounts in root than in leaf and may be of use in distinguishing the part of the plant from which ground up material originated.

There may be a limited use for dispensable HLY in distinguishing var. ' $L$ ' from var. ' $T$ ', at least when grown under specific conditions, and for monitoring peat sensitivity in some future M. expansa studies. These potential uses for HLY require further testing. HLY used alone is unlikely to be useful as an indicator for monitoring effects due to variety or peat. Dispensable LAN did not produce meaningful results in any of the pair-wise combinations for any model, as it was absent from the samples even though it was addressed in the assays.

Dispensable ORN production was extremely low and undetected in the field. ORN was only produced in the green house, indicating that at least for this one amino acid, growth conditions may turn production on or off in the crop. Perhaps there is an epigenetic component to ORN production and this might hold implications for production of other amino acids in $M$. ex- pansa as well. This would be in keeping with the epigenetic flexibility suspected by Kritzer Van Zant for morphological expression by $M$. expansa. Epigenetic variation is also a possible explanation for repeated variations in other Nyctaginaceae such as the tree genus Neea, which varies the number of leaves at a node. The family has many similar examples of morphological flexibility. Or, it may just be that the amount of ORN produced in that individual sample was just sufficient in quantity to cross the threshold of sensitivity in the amino acid profile assay, while production in other samples was present in amounts just below the threshold for recognition.

Several combinations of independent variables without any of the variety ' $T$ ' greenhouse data, gave no significant results in any ANOVA for either independent variable. Further, these same pairs of variables often produced no results at all for many dependent variables. Variety x COA (EXT Table 4), produced no results for variety both with and without the interaction term request in the ANOVAs, and produced no significant results for the interactions. In the ANOVAs for variety x peat (EXT Table 5), variety $\mathrm{x}$ steer manure (EXT Table 6), and peat x steer manure (EXT Table 10), each independent variable and interaction term request either had no results, or were not significant for any interaction.

For the independent variable structure within the ANOVAs for structure $\mathrm{x}$ variety (EXT Tables 1, 2 and 3), most of the indispensable amino acids were highly significant with and without the interaction term. Only indispensable TRP reflected its own pattern for structure within the ANOVA for structure $\mathrm{x}$ variety, significant without the interaction term request and highly significant with the interaction term request, and only in Table 1 which had all of the greenhouse data included. In EXT Tables 2 and 3, all indispensable amino acids, CRDP and TOTP, were highly significant.

Data for whole models was included in Kritzer Van Zant (2016a), so the interested reader can see how the pair-wise component variables affected ANOVAs overall, and differences between models with and without requests for interaction terms. However, based on the other analyses using the same variables, one of the paired variables was typically considerably more responsible than the other variable in the pair, for the presence and degree of or lack of significance.

Imbalances in the data compelled the one-by-one approach to the independent variables. Causes of imbalances included similar though mismatched treatments with organic amendments in plots for the two varieties, breakdown of COA plots to their component amendments for statistical purposes while ignoring the presence of the other amendment present in only some of the plots included in the analyses, lack of a stem sample for var. ' $L$ ', only one leaf field sample for var. ' $T$ ', using field material for the two varieties grown in different years and submitting them for amino acid profiling separately in different years; utilizing greenhouse-grown material for one leaf sample and for the stem sample for var. ' $T$ ' to represent the above ground material for that variety while all var. ' $L$ ' samples were field grown, compounded by stem having a profile closer to root than to leaf, the very small number of samples profiled, and the lack of randomness in selection of the remaining samples for amino acid profiling.

Much of the South American information on growing M. expansa (Kritzer Van Zant, 2016a, b, 2017) was not available to us until after the southern Illinois outdoor growth trials were com- 
pleted (Kritzer Van Zant et al., 2018). In addition, the South American material on growing $M$. expansa was less detailed than the information from the southern Illinois growth study (Kritzer Van Zant, 2016a, b, c; Kritzer Van Zant et al., 2018). Figuring out how to grow M. expansa outdoors, based on what we had learned while growing it in the greenhouse, was the original intent of the field study, though hypotheses were written prior to running the ANOVA and LS-Means analyses. Vivanco, Flores and colleagues work at Colorado State University was done on a mixture of imported M. expansa from South America and Colorado greenhouse-grown material, as it did not survive in Colorado in the field (J.M. Vivanco, personal communication, 2008). We suspect that the Colorado researchers were not aware of the unusual watering needs of the crop, and its high sensitivity to too much water, which became obvious during the southern Illinois field and greenhouse work. The plants cannot tolerate standing water, which is characteristic of most southern Illinois native soils at various times during the growing season. Thus, a special area of artificially constructed sand plots was the only place where the plants were grown successfully in the field. The choice and availability of these plots was limited and not fully consistent from year to year. It was necessary to use most of the same plots used for var. ' $L$ ' for two years, to obtain repeat data for statistical purposes. Var. ' $T$ ' was grown in 2009 on some other plot types, which had also been used to grow var. ' $L$ ' on a terrace not available for this purpose in 2008. However, those plots did not produce a harvest in 2009, leaving only var. ' $T$ ' grown on slightly different treatments than var. ' $L$ ', to analyze. 